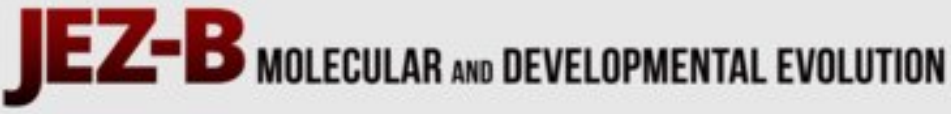

\section{Ovarian transcriptomic signatures of zebrafish females resistant to different environmental perturbations}

\begin{tabular}{|c|c|}
\hline Journal: & JEZ Part B: Molecular and Developmental Evolution \\
\hline Manuscript ID & Draft \\
\hline Wiley - Manuscript type: & Research Article \\
\hline $\begin{array}{r}\text { Date Submitted by the } \\
\text { Author: }\end{array}$ & $n / a$ \\
\hline Complete List of Authors: & $\begin{array}{l}\text { Valdivieso, Alejandro; CSIC, Institut de Ciències del Mar, Barcelona } \\
\text { Ribas, Laia; CSIC, Institut de Ciencies del Mar, Barcelona } \\
\text { Piferrer, Francesc; Instituto de Ciencias del Mar (CSIC) }\end{array}$ \\
\hline Keywords: & $\begin{array}{l}\text { environmental stress, density, temperature, gonad, molecular markers, } \\
\text { masculinization }\end{array}$ \\
\hline
\end{tabular}




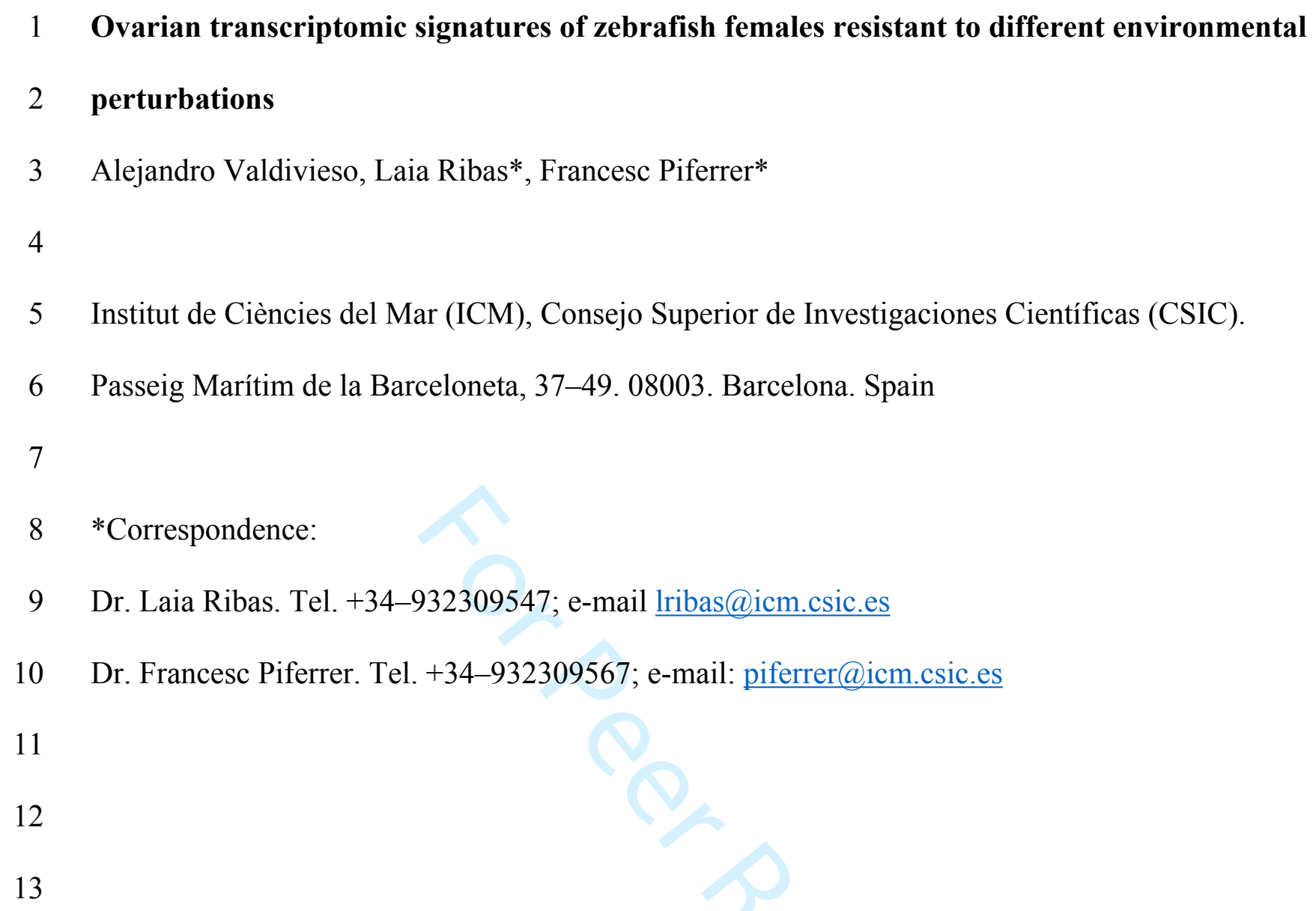




\section{Abstract}

27 Sex is remarkably plastic in fish and can be easily influenced by environmental cues, of which

28 temperature has been the most studied abiotic factor. However, although it has been shown that

29 elevated population densities can increase the number of males in several species, little is known

30 about the underlying molecular mechanisms and whether general patterns exist. Here, we studied

31 the long-term effects of population density on the gene expression program in zebrafish gonads.

32 The ovarian transcriptome of females exposed to high $v$ s. low population densities contained

33 4,341 differentially expressed genes. Among them, a set of pro-male genes (amh, sypc3, spata6

34 and sox3) upregulated in the ovaries was identified. Next, we compared the transcriptomes of

35 ovaries of female zebrafish resistant to the masculinizing effects of either high density or elevated

36 temperature. Results showed a set of 131 and 242 common upregulated and downregulated

37 genes, respectively, including the upregulation of known male-related genes (e.g., amh and

38 sycp3) but also genes involved in other functions (e.g., faima ccm21, ankrd6b) and a

39 downregulation of cyp19ala together with other genes (e.g., lgals9l1, ubxn2a). We identified

40 common GO-terms involved in reproduction and sexual development that were consistently

41 affected in both environmental factors. These results show that regardless of the environmental

42 perturbator there are common genes and cellular functions involved in the resistance to

43 masculinization. These altered gene expression profiles can be used as robust markers indicative

44 of previous exposure to environmental stress independent of conspicuous alterations in sex ratios

45 or gonadal morphology.

47 Key words: environmental stress, density, temperature, gonad, molecular markers, 48 masculinization 


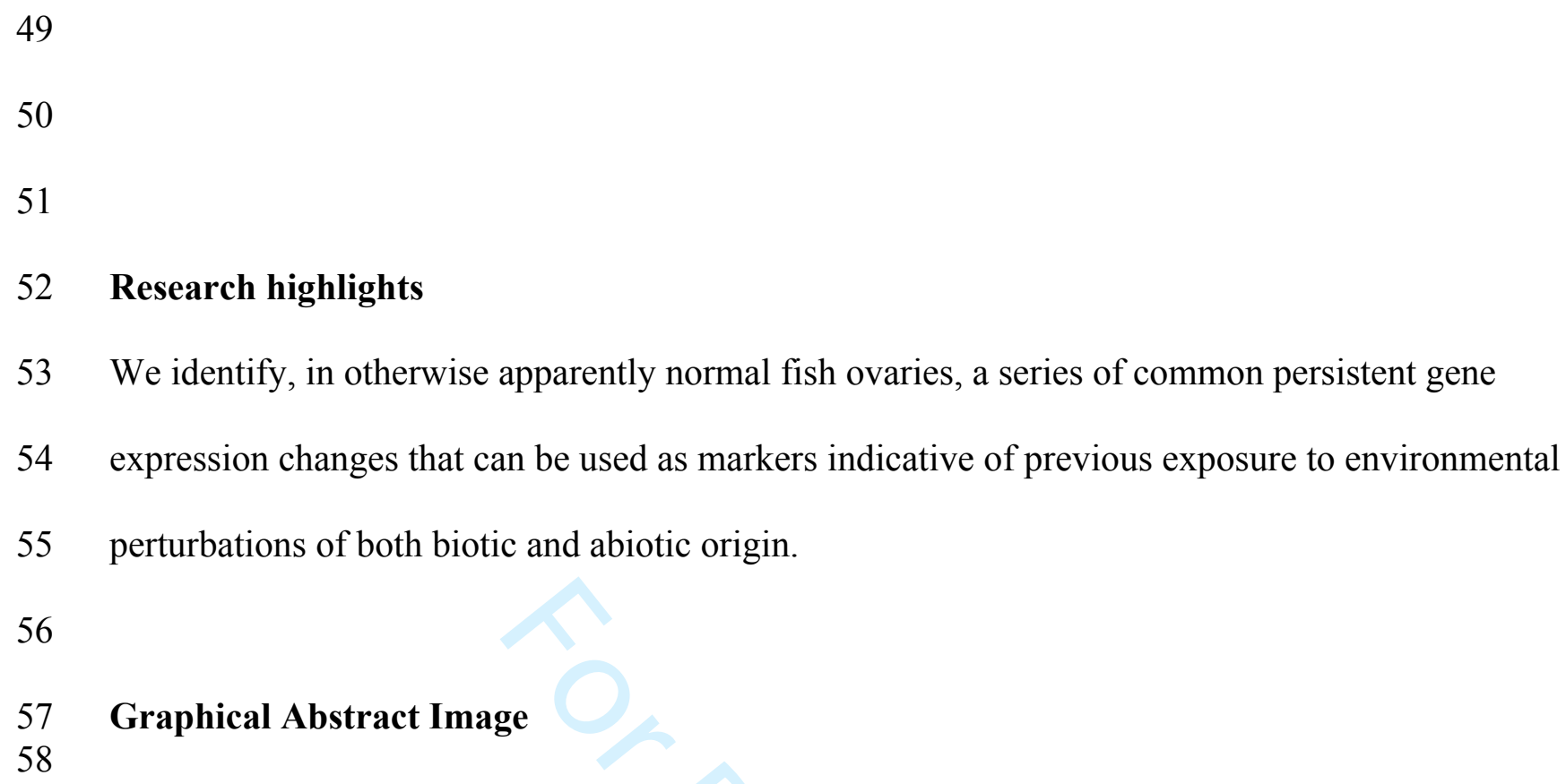

53 We identify, in otherwise apparently normal fish ovaries, a series of common persistent gene

54 expression changes that can be used as markers indicative of previous exposure to environmental 55 perturbations of both biotic and abiotic origin.

57 Graphical Abstract Image

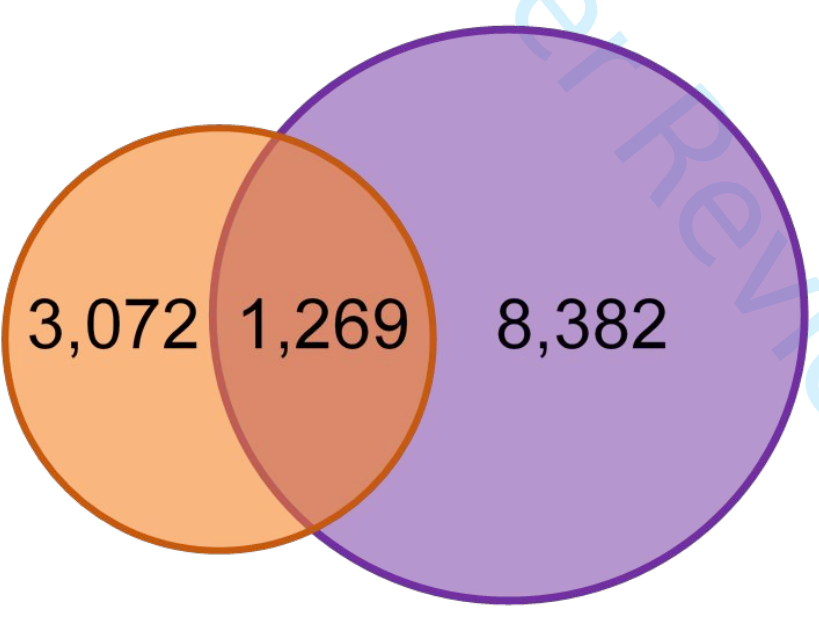




\section{Introduction}

79 In fish, some environmental factors can be perceived as stressors if their magnitude exceeds a

80 certain threshold for a given species at a particular sensitive developmental time. The

81 consequences can be ample, including alterations of physiology, reproduction and sex ratios.

83 Sex determination in fish can be regulated by genetic factors (genetic sex determination, GSD) by

84 influences of the environment (environmental sex determination, ESD) or a combination of both

85 (Devlin \& Nagahama, 2002; Penman \& Piferrer, 2008). In GSD species, sex can be determined

86 by the action of single or master gene, by the action of a master gene plus secondari loci or by the

87 combined action of several autosomal genes, the latter called polygenic sex determination (PSD).

88 In ESD, sex can be influenced by different abiotic and biotic factors, of which temperature and

89 population density are the most common ones (Penman \& Piferrer, 2008; Valenzuela, 2008).

90 Nowadays, GSD and ESD are not considered necessarily mutually exclusive and, hence, are

91 regarded as the two ends of a continuum (Sarre et al., 2004; Heule et al., 2014; Yamamoto et al.,

$92 \underline{2014})$.

94 For poikylothermic animals like fish, temperature is perhaps the most important abiotic factor.

95 Abnormally elevated temperatures can masculinize many species if exposure takes place during

96 the process of sex differentiation or earlier (Ospina-Alvarez \& Piferrer, 2008). The masculinizing 
97 effect of elevated temperature takes place regardless of the underlying sex determining system 98 and thus have been observed in species with male heterogamety $(\mathrm{XX} / \mathrm{XY})$ such as, for example, 99 the rainbow trout (Oncorhynchus mykiss) (Valdivia et al., 2014) or the Nile tilapia (Oreochromis 100 niloticus) (Baras et al., 2001); and species with polygenic sex determination such as the European 101 sea bass (Dicentrarchus labrax) (Saillant et al., 2002; Diaz \& Piferrer, 2015).

103 Regarding population density, it was found that elevated density in the Paradise fish

104 (Macropodus opercularus) (Francis, 1984) and in the European eel (Anguilla anguilla)

105 (Roncarati et al., 1997; Huertas \& Cerdà, 2006) was able to skew sex ratio towards males. In

106 contrast, in the European sea bass no effects were observed when fish were confined during early 107 stages of development (Saillant et al., 2003). In zebrafish (Danio rerio), elevated density resulted 108 in male-biased sex ratios (Ribas et al., 2017b) with inter-family variation (Liew et al., 2012;

109 Ribas et al., 2017c) due to genetic $\mathrm{x}$ environmental interactions.

111 Zebrafish is a small cyprinid widely used as an animal model in many research areas. Wild 112 zebrafish strains exhibit a GSD system of the ZW/ZZ type, with a putative sex master gene 113 located in the telomeric region of chromosome 4 (Wilson et al., 2014). In contrast, in the two 114 most used laboratory strains (AB and TÜ) this system was not detected probably due to the loss 115 of the sex determining region during the domestication process (Wilson et al., 2014). Because of 116 this, domesticated zebrafish behave as a PSD system with elevated sensitivity to environmental 117 perturbations (Liew et al., 2012; Ribas et al., 2017a) which explains why zebrafish facilities

118 across the world usually encounter skewed sex ratios. Thus, laboratory strains of zebrafish 119 constitute indeed a good model where to study the effects of environmental perturbations on the 120 developing gonads and the resulting sex ratios. 
122 Sex differentiation in zebrafish starts from 10 until 45 days post fertilization (dpf). In all

123 individuals, gonads first develop as an ovary-like immature tissue (Takashi, 1977). Later, ovarian

124 differentiation continues in about half the individuals whereas in the remaining apoptosis takes

125 place and the ovarian tissue regresses and is progressively substituted by testicular tissue (Uchida

126 et al., 2002; von Hofsten \& Olsson, 2005; Orban et al., 2009). The stress resulting from exposure

127 to elevated temperature during the period of sex differentiation results in masculinization (Uchida

128 et al., 2004; Abozaid et al., 2012; Brown et al., 2015; Ribas et al., 2017a) and thus there are some

129 sex-reversed females (referred to as "neomales") (Pandian \& Sheela, 1995). In addition to regular

130 males and females, two additional transcriptomic profiles were identified in heat-treated fish: the

131 neomales and a novel type of females. These were phenotypic females but with a male-like

132 transcriptomic profile, where an upregulation of male-related genes (e.g., amh, dmrtl) and a

133 downregulation of female-related genes (e.g., cyp19ala, foxl2a, vtg2) was observed (Ribas et al., $134 \quad 2017 \mathrm{a})$.

136 Further, regardless of type of stressor (temperature or density), a common physiological response 137 is the increase plasma cortisol levels (Ramsay et al., 2006, 2009; Yeh et al., 2013). This is a

138 protective mechanism in response to stress that helps to regulate basal homeostasis (Bonga,

139 1997). It is well established that chronic stress has adverse effects in growth and reproduction

$140(\underline{\text { Schreck, 2010) }})$ but recently it has also been demonstrated that elevated cortisol levels due to

141 stress are associated with masculinization (Hattori et al., 2009; Fernandino et al., 2012;

142 Fernandino et al., 2013). Further, oral administration of cortisol during early development

143 resulted in complete masculinization in zebrafish (Ribas et al., 2017b). 
145 However, the knowledge about the underlying mechanisms responsible for the masculinization of

146 the gonads in response to environmental perturbations is still fragmentary. Further, nothing is

147 known about possible hidden alterations, particularly in resistant females, which exhibit an

148 otherwise apparently normal ovarian morphology. Thus, to date most gonadal transcriptomic

149 studies have been focused on the sex-related differences in adult gonads: Olive flounder

150 (Paralichthys olivaceus) (Fan et al., 2014); yellow catfish (Pelteobagrus fulvidraco) (Lu et al.,

151 2014); zebrafish (Sreenivasan et al., 2008; Small et al., 2009). Few studies reported the

152 influences of elevated temperature on the gonadal transcriptomes, one in zebrafish (Ribas et al.,

153 2017a) and the other in the Nile tilapia (Sun et al., 2018). However, to our knowledge, there are

154 no transcriptomic studies of the effects of density in fish gonads. For this reason, the first

155 objective of this study was to analyze the gonadal transcriptome of zebrafish exposed to elevated

156 density during sex differentiation. The second objective was to compare this data against

157 transcriptomic data of females exposed to elevated temperature from previous experiments

158 reported in our lab (Ribas et al., 2017a). The ultimate goal was to identify a series of common

159 persistent gene expression changes that can be used as markers indicative of previous exposure to

160 environmental perturbations of both biotic and abiotic origin.

162 Materials and methods

\section{Gonad samples and gonadal maturation data}

164 Gonad maturation data and RNA samples of zebrafish exposed to different rearing were obtained

165 from fish described in "Experiment 1: effects of stocking density" in Ribas et al. (2017b). Briefly,

166 the zebrafish larvae from four independent families were reared from 6 to $90 \mathrm{dpf}$ at four different

167 densities: 9 (control, low density, LD), 17, 37 and 74 (high density, HD) fish/litre. At $90 \mathrm{dpf}$ 
168 gonads were dissected and classified according to the degree of maturation as immature (type 1),

169 maturing (type 2) or mature gonad (type 3) (Ribas et al., 2017a).

$171 \quad R N A$ extraction and $c D N A$ synthesis and primers

172 RNA was extracted from $n=8$ fish per sex and density ( $n=16$ for each density) for qPCR

173 analysis (Table S1) using $400 \mu 1$ of Trizol reagent (Invitrogen, CA, USA). RNA quality was

174 measured with a NanoDrop 1000 spectrophotometer (260/230 and 260/280 nm absorbance

175 ratios). After removing the genomic DNA with DNase I (Deoxyribonuclease I Amplification

176 Grade, Invitrogen, CA, USA), the cDNA was synthesized from 200 ng of RNA using SuperScript

177 III reverse transcriptase (Invitrogen, CA, USA). Specific primers for target genes were designed

178 using Primer Express ${ }^{\circledR}$ (v3.0) software (Applied Biosystems, USA) and purchased from

179 Invitrogen (Life Technologies, UK). Primers were designed within the inter-exon regions. Primer

180 efficiencies were cheeked in a pool of male and female cDNA gonad samples by using serial

181 dilutions $(1,1 / 10,1 / 501 / 100$ and 1/500). Melting curve analysis was also performed to validate

182 the size of the expected PCR product. The $\mathrm{qPCR}$ reactions were performed on a QuantStudio ${ }^{\mathrm{TM}}$

183 12K Flex System (Applied Biosystems, Life Technologies) using $2 \mu 1$ of SYBR Green PCR

184 master mix (Applied Biosystems), $0.5 \mu \mathrm{l}$ for each forward and reverse primers and $2 \mu \mathrm{cDNA}$

185 (1/10 dilution) in a total reaction volume of $10 \mu \mathrm{l}$ per well. The qPCR cycle parameters were an

186 initial denaturing step at $95^{\circ} \mathrm{C}$ for $10 \mathrm{~min}$, followed by 40 cycles of $95^{\circ} \mathrm{C}$ for $30 \mathrm{~s}$ and $60^{\circ} \mathrm{C}$ for 1

187 min with negative controls. For each sample, the reactions were done in triplicate and the average

188 threshold cycle was calculated using the $2^{-\Delta \Delta \mathrm{Ct}}$ method (Livak \& Schmittgen, 2001). Relative

189 gene expression data were normalized against a reference gene, the eukaryotic translation

190 elongation factor 1 alpha 1, like 1 (eeflall1), previously validated in zebrafish (McCurley \& 
191 Callard, 2008). The gene symbol, gene name, accession number and forward and reverse

192 sequences for each primer pair used in this study are summarized in the Table S2.

194 Microarray analysis of ovaries obtained from fish exposed to high density

195 For microarray analysis, the control group ( 9 fish/liter) and the group exposed to the highest

196 density (37 fish/liter) were used (from now on referred to as the LD and HD groups,

197 respectively). From each group, 6 out of the 8 gonad samples used for qPCR were also used

198 (Table S3) for microarray analysis and hybridized individually in a $4 \times 44 \mathrm{~K}$ Agilent platform

199 (G2519F-026437) at the Barcelona Biomedical Research Park (PRBB). Briefly, the cRNA

200 generated from the mRNA of each ovarian sample were prepared for overnight hybridization

201 with the corresponding buffers during $17 \mathrm{~h}$ at $65^{\circ} \mathrm{C}$ and washed on the following day. Hybridized

202 slides were scanned using an Agilent G2565B microarray scanner (Agilent Technologies, USA).

203 The results were deposited in Gene Expression Omnibus database (GEO), with the accession

204 number GSE116700.

205

206 Common genes and pathways in ovaries of females exposed to either high density or high

207 temperature

208 Gene expression differences of HD vs. LD females were compared with those of high

209 temperature (HT) vs. low temperature (LT) females, specifically, the females named as FHT2 vs.

210 LT females, described in Ribas et al. (2017a). These FHT2 females were females with apparently

211 normal ovarian morphology but with a male transcriptome. Importantly, the ovarian samples

212 from the density and temperature experiments to be compared had in common: (i) both

213 experiments were performed at the same fish facility; (ii) the laboratory strain used was AB; (iii)

214 the conditions in the control treatments in each experiment (groups LD and LT) were the same: 
215 rearing density of 9 fish/litre and water temperature $28 \pm 1^{\circ} \mathrm{C} ;(i v)$ exposure to the environmental

216 perturbations included the sex differentiation period; $(v)$ and all fish were sampled at the same

217 age: 90 dpf.

218

219 Statistical analysis of the data

220 Differences in the proportions of gonad types were analyzed by the Chi-squared test. For the

221 qPCR $\Delta \Delta$ Ct data, normality was checked with the Kolmogorov-Smirnov test and logarithmic

222 transformations were applied when necessary. The homoscedasticity of variances was checked

223 with the Levene's test. Means were compared by one-way analysis of variance (ANOVA) with a

224 Tukey's post-hoc multiple range test. Significant differences were accepted when $P \leq 0.05$. Data

225 were analyzed by the StatGraphics Centurion (v. 17) software (Open Land, Inc.).

227 Microarray raw data was processed by Agilent software to avoid saturation and generate feature

228 extraction. The output data were statistically analyzed by R (http://www.R-project.org) language

229 and array normalization was implemented by Quantile method in the Limma package (Smyth \&

230 Speed, 2003). To determine differentially expressed genes (DEGs), an adjusted $P$-value $\leq 0.05$

231 and fold change (FC) $\geq 1.2$ was used as threshold. Microarray validation was carried out by

232 studying the expression of 14 DEGs by qPCR analysis. Gene ontology categories (GO-terms) and

233 Kyoto Encyclopedia of Genes and Genomes (KEGG) pathways from the DEGs were obtained by

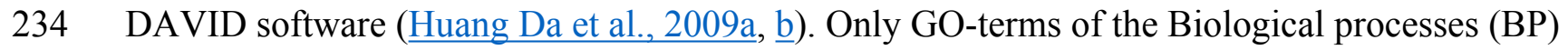

235 category level 2 with an EASE Score (a modified Fisher Exact $P \leq 0.05$ ) with a minimum of

236 three genes belonging in specific GO-term was considered relevant. The significant GO-terms

237 were plotted by REVIGO software (Supek et al., 2011). The R software (v 3.4.2) (Team, 2013) 
238 was used with the packages ggplots (v 2.2.1) and gplots, (v 3.0.1) to edit the REVIGO graph and 239 to generate heatmap figures, respectively.

241 Results

242 High density affected gonadal maturation in females and males

243 Elevated rearing density not only masculinized zebrafish in a density-dependent manner (Ribas et

244 al. (2017a) but in both sexes, there was a progressive increase in the proportion of fish with type

2451 (immature) gonads with increasing rearing density and, conversely, a progressive decrease in

246 type 3 (mature) gonads. Significant effects $(P<0.05)$ in the change of proportions with respect to

247 the control group (9 fish/liter) were observed with rearing densities of $37 \mathrm{fish} /$ liter and above

248 (Fig. S1).

High density downregulated gene expression of cyp19a1 a in ovaries and nr3c1 in both sexes

251 In an exploratory phase of the data, qPCR was used to evaluate how density affected the

252 expression of selected genes related to sexual development and the stress response. In ovaries, the 253 expression of cyp19ala was significantly downregulated at a density of 74 fish/liter (Fig. 1A),

254 while the expression of forkhead box L2a (foxl2a) was unaffected (Fig. 1C). In testes, the 255 expression levels of double sex and mab-3 related transcription factor $1($ dmrtl $)$ (Fig. 1B) and the 256 anti-Müllerian hormone $(\mathrm{amh})$ (Fig. 1D) was reduced but differences were not significant. The

257 stress response was assessed by the nuclear receptor subfamily 3 group $\mathrm{C}$ member 1 gene

258 ( $n r 3 c 1)$, also known as the glucocorticoid receptor (GR), which showed a significant

259 downregulation in both ovaries (Fig. 1E) and testes (Fig. 1F). These results indicate that elevated 260 rearing density affected both sexes. 


\section{Transcriptomic overview and microarray validation}

263 Next, a species-specific and validated microarray was used to compare the transcriptomes of 264 females of the HD group, i.e., the females that did not become masculinized. These females were 265 compared with control females. Results showed a total of 4,341 DEGs (adjusted $p$-value $P \leq$ $2660.05, \mathrm{FC}>1$ ) between the ovaries of fish reared at HD and LD (Dataset S1). Microarray data 267 was fully validated by qPCR in a subset of selected genes covering a \pm 4 range of FC values $\left(\mathrm{R}^{2}=\right.$ $268 \quad 0.83$ and $\mathrm{P}=0.0001)$ (Fig. S2).

270 GO-terms associated in ovaries of females exposed to high density

271 From the up-and downregulated DEGs, a total of 16 and 15 up- and downregulated GO-terms, 272 respectively, were found associated with the BP category (Fig. S3). Among the upregulated GO273 terms (Fig. S3A), the most important subcategories were related to reproduction: anatomical 274 structure morphogenesis (GO:0009653) and developmental process involved in reproduction 275 (GO:0003006). The former, was represented by 14 genes, of which three are involved in pro276 male pathways ( $a m h$, sox3 and $l h b)$, two related to meiosis (mei4 and sycp3) and two genes were 277 ovarian markers (zp3a.2 and $z p 3 b)$. Of the downregulated GO-terms (Fig. S3B), some were 278 related to reproduction, stress, immunity and growth. For example: anatomical structure 279 formation involved in morphogenesis (GO:0048646), anatomical structure in morphogenesis 280 (GO:0009653), immune responses (GO:0006955), responses to external stimulus (GO:0009605), 281 responses to stress (GO:0006950) and developmental growth (GO:0048589).

High density promoted the upregulation of pro-male genes in the ovaries

284 All the DEGs were compared against two independent lists of genes related to sex and stress 285 responses. One list included a total of 48 genes with proven sex-related functions in zebrafish, as 
286 described in Ribas et al. (2017a), while the other list included genes with proven stress-related 287 responses, as described in Eissa and Wang (2016). The common DEGs obtained for each of the 288 two lists were used for heatmap construction. A total of 24 and 20 genes related to reproduction 289 and stress, respectively, were identified (Fig. 2), and allowed the clustering of all but one sample 290 according to rearing density. Regarding sex-related genes (Fig. 2A), some male-related genes

291 (i.e. amh, sypc3, spata6 and sox3) were upregulated in HD ovaries whereas cyp 19ala was 292 downregulated, confirming our previous gene expression results obtained by qPCR. Regarding 293 stress-related genes (Fig. 2B), 15 out of the 20 genes shown in the heatmap were downregulated 294 in the HD group (e.g., nudt3b, hmox 2b, b2nl, cnr 1) and five (nud, hsp14, duox, mstnb, hsp 295 90aa.1.1) were upregulated.

297 Common genes in ovaries of females subjected to high density or high temperature

298 Elevated rearing density or temperature during the sensitive period of sexual development result 299 in masculinization of some females (Fig. S4), which is easy to quantify by sex ratio analysis.

300 However, while all non-masculinized females have apparently normal ovaries, at least

301 morphologically, at least some females can have an altered transcriptome, sometimes more

302 similar to that of males than to that of unexposed females. Here, we wanted to know what the 303 ovaries of resistant females have in common regardless of whether fish have been exposed to 304 elevated density or temperature. Thus, we compared the reported ovarian transcriptomic results 305 of the HD vs. the LD groups with those obtained comparing the HT vs. LT groups previously 306 described in our laboratory (Ribas et al., 2017a). We found 1,269 DEGs (Fig. S5) commonly 307 regulated and were represented according to their FC (Fig. 3A) and to their expression tendency 308 (Fig. 3B). We classified them in four sets (Dataset 2): set A ( $\mathrm{n}=131)$ genes that were consistently 309 upregulated by density and temperature; set $\mathrm{B}(\mathrm{n}=550)$ genes that were upregulated by density 
310 but downregulated by temperature; set $\mathrm{C}(\mathrm{n}=346)$ genes that were downregulated by density but

311 upregulated by temperature and set $\mathrm{D}(\mathrm{n}=242)$ genes that were consistently downregulated by

312 both factors. Further analyses were done with the sets A and D and we selected the top ten genes

313 by the highest FC as a result of HD (Table 1). In set A, we found, for example the fas apoptotic

314 inhibitory molecule a (faima), tyrosine phosphatase containing 1 (ptpdcla) and cerebral

315 cavernous malformation 2-like ( $\mathrm{ccm} 2 l)$ genes. The set D contained, among others, galectin 9

316 (lgals9l1), deoxyribonuclease II lysosomal (dnase2) and the cyp19ala genes.

318 Common GO-terms in ovaries of females subjected to high density or high temperature

319 We analyzed separately the genes of the set A and D by DAVID to inquire into the BP GO-terms.

320 There were a total of nine GO-terms in set A (Fig. 4A) including cellular component organization

321 (GO:0016043) and negative regulation of response to stimulus (GO: GO:0048583); and eight

322 GO-terms in set D (Fig. 4B), including cellular metabolic process (GO:0044237) and methylation

323 (GO:0006306). The three most significant GO-terms in set A were single-organism

324 developmental process (GO:0044767), single-multicellular organism process (GO:0044707) and

325 anatomical structure morphogenesis (GO:0009653) (Fig. 5A, B and C), whereas in set D were

326 macromolecule localization (GO:0033036), primary metabolic process (GO:0044238) and

327 cellular metabolic process (GO:0044237) (Fig. 5D, E and F). Next, for exploratory analysis, we

328 looked at the top three genes (with the highest FC in the density experiment) in order to further

329 identify those genes commonly altered in both perturbations (Table S4). For example, in the

330 single-multicellular organism process, we found kinase D-interacting substrate 220b (kidins220b)

331 gene upregulated 1.93 and 3.77 times in the density and temperature experiments, respectively,

332 and in the primary metabolic process GO-term, we found UBX domain protein $2 \mathrm{~A}(u b x n 2 a)$ gene

333 downregulated -4.3 and -3.98 times in the density and temperature experiments, respectively. 
334 Interestingly, $\mathrm{FC}$ values of genes altered by temperature were higher those altered by density 335 (Fig. 6A).

336

337 KEGG pathways in ovaries of females subjected to high density or high temperature

338 There were no common KEGG pathways related to the DEGs conforming the A or D sets,

339 probably due to the relatively low number of genes in each set. However, the expression of genes

340 involved in reproduction-related KEGG pathways in zebrafish (Ribas et al., 2017a), namely, the

341 Wnt signalling (dre04310), homologous recombination (HR, dre03440), transforming growth

342 factor- $\beta$ (TGF- $\beta$, dre04350), oocyte meiosis (OM, dre04114), p53 signalling (dre04115) and

343 steroid hormone biosynthesis (SHP, dre00140) pathways had the same direction of change

344 regardless of perturbation (Fig. 6B). In the Wnt signalling pathway, there were two

345 downregulated genes (axin 2 conductin-axil, axin2 and protein kinase cAMP-dependent catalytic

346 alpha genome duplicate b, prkacab) and one upregulated gene (transforming protein RhoA,

347 rhoa). Rhoa also belongs to the TGF- $\beta$ pathway together with $a m h$, which was also upregulated.

348 In the HR signalling pathway, sycp 3 was upregulated. The phosphatase and tensin homolog B

349 (ptenb), golgin rab6-interacting (gorab), the F-box protein 5 (fbxo5) and cyp19ala genes

350 belonging to the p53 signalling, OM and SHP pathways, respectively, were downregulated.

352 The KEGG pathways from the 4,341 DEGs found in the density experiment were compared to

353 the KEGG pathways reported in the ovaries of those resistant females treated with elevated

354 temperature (Ribas et al., 2017a) and no common pathways were found, so we listed in Table 2 ,

355 the significant up-and downregulated KEGG pathways found in the density experiment and the

356 four most significant up-and downregulated KEGG pathways found in the temperature

357 experiment. In particular, in the ovaries of fish subjected to density, we found an upregulation of 
358 the gonadotropin-releasing hormone receptor pathway (dre04080) and a downregulation of five

359 KEGG pathways, for example, the integrin signalling pathway (dre04510). For the temperature

360 factor, the most up-and downregulated pathways were the cardiac muscle contraction (dre04260)

361 and the protein processing in endoplasmic reticulum (dre04141).

362

363 Discussion

364 Fish gonadal development is quite plastic and in many species, the response to environmental

365 perturbations that encompass the period of sex differentiation is masculinization (Ospina-Alvarez

366 \& Piferrer, 2008; Baroiller \& D'Cotta, 2016; Piferrer, 2018). The masculinization of genotypic

367 females generates phenotypic males (Hliwa et al., 2013) that are termed neomales (Pandian \&

368 Sheela, 1995). These neomales are capable of producing viable sperm (Piferrer, 2001). The

369 remaining females, i.e., non-masculinized females, were thought to be regular females resistant to

370 elevated temperature. However, recently it was found in zebrafish exposed to HT that some of

371 these females in fact have a male-like transcriptome (Ribas et al., 2017a). In the present study, we

372 showed that these females with apparently normal morphology but with a male-like

373 transcriptome also appear in populations partially masculinized by elevated rearing density and

374 consequently we were interested in finding out what are the common transcriptomic signatures of

375 these resistant fish. Our data, therefore, not only provides the first comprehensive ovarian

376 transcriptomic analysis of the long-term effects of elevated population density, but also identify

377 common markers of previous environmental perturbation regardless of the type of perturbation.

378

379 Elevated population densities progressively delayed gonadal development in males and in

380 females, coinciding also with the progressive masculinization observed earlier (Ribas et al.,

$3812017 \mathrm{~b}$ ). This maturation delay was also observed in the gonads of zebrafish subjected to high 
382 temperatures (Ribas et al., 2017a), although in that case it was only significant in males, probably

383 due to the shorter duration of the exposure to temperature when compared to density.

385 A set of canonical sex-related genes were measured in the gonads of fish exposed to elevated 386 density. In the ovaries, the expression of cyp19ala, was downregulated at the highest density 387 while the expression of foxl2a, a transcriptional regulator of cyp19ala (Wang et al., 2007), 388 remained stable, probably due to the fact that foxl2 has two transcript variants: foxl $2 a$ and foxl $2 b$, 389 and both transcripts cooperate to regulate development and maintenance of the ovary (Yang et

390 al., 2017) and it is possible that the other variant could be expressed instead. The downregulation 391 of cyp19ala in ovaries was described in zebrafish exposed to elevated temperature (Ribas et al., 392 2017a) and to hypoxia conditions (Shang et al., 2006) as well as in other fish species such as the 393 Japanese flounder (Kitano et al., 1999) and in the European sea bass (Navarro-Martín et al., 2011;

394 Diaz \& Piferrer, 2015) when subjected to high temperatures. Thus, environmental stress reduces

395 the expression of cyp19ala in the gonads and this is in agreement with the observed 396 masculinization since that cyp19ala is necessary for ovarian development, as demonstrated in 397 loss-of-function experiments (Lau et al., 2016)(de Castro Assis et al., 2018). In testes, dmrt1, a 398 transcription factor that plays a key role in male sex determination in zebrafish (Webster et al., 399 2017), and $a m h$, a gene involved in male sexual differentiation by suppressing estrogen 400 production (Rodriguez-Mari et al., 2005), did not show differences in gene expression due to 401 high density confinement, suggesting no conspicuous effects of density at least in these two 402 important genes for male sexual differentiation, although this, of course, does not exclude 403 possible effects on genes related to spermatogenesis, which were not the focus of this study. 404 
405 It is known that abiotic and biotic stressors modulate the synthesis of cortisol altering the

406 expression of genes of the hypothalamic-pituitary-interrenal (HPI) axis (Alsop \& Vijayan, 2008;

407 Alsop et al., 2009). The GR gene, a ligand-activated nuclear receptor, has a high binding affinity

408 to cortisol and acts in inflammatory responses, cellular proliferation and differentiation in target

409 tissues (Beck et al., 2009). Fish subjected to chronic stress showed lower GR levels in brain

410 (Piato et al., 2011). Further, changes in rainbow trout GR expression levels in the HPI axis were

411 found after 7 days of confinement (Kiilerich et al., 2018). Since cortisol exerts different effects

412 on various organ systems, it is likely that the functional targets of GR are different in each tissue

413 (Le et al., 2005). Cortisol plasma levels increased after 7 and 14 days of chronic confinement in

414 sea bream (Sparus aurata) (Barton et al., 2005) and rainbow trout (Kiilerich et al., 2017),

415 respectively, but their levels were recovered in longer confinement experiments (e.g., 200 days

416 in wedge sole, Dicologoglossa cuneate (Herrera et al., 2015). In a similar manner, no difference

417 in cortisol levels were found in juvenile zebrafish subjected to high density during 45 days (Ribas

418 et al., 2017b) but, when mature, GR was downregulated in the gonads at the highest densities

419 especially in females. This is, to our knowledge, the first time that a downregulation of GR in the

420 gonads due to chronic stress is reported, since it was not observed in reproductive tissues when

421 zebrafish were exposed, for example, to elevated temperature (Ribas et al., 2017a). The

422 downregulation found of GR in the gonads was probably to attenuate the physiological effects

423 due to the stress.

425 Prolonged rearing at high population density affected the expression of more than 4,300 genes in 426 the ovaries of non-masculinized females. Further, analysis of the combined expression levels of 427 only 24 genes related to reproduction and 20 to stress was sufficient to clearly distinguish ovaries 428 of fish subjected to elevated density from those of control fish, indicating that these selected 
429 genes could be used as potential molecular markers of elevated population density. Microarray 430 analysis evidenced a downregulation of cyp19ala, as previously found by qPCR analyses, and an 431 upregulation of a set of genes involved in the pro-male pathway. These male genes were $a m h$, 432 sycp3, a gene that is a spermatocyte marker for meiotic cells (Ozaki et al., 2011; Saito et al., 433 2011), sox3, a gene associated with male development (Sutton et al., 2011), and spata6, 434 necessary for the correct progression of spermatogenesis (Yuan et al., 2015). However, other 435 genes were downregulated: the steroidogenic factor 1 ( $n r 5 a 1)$ required for testis development 436 (Wilhelm \& Englert, 2002) and the androgen receptor (ar). The results were in concordance with 437 those previously described in zebrafish females exposed to elevated temperature (Ribas et al., 438 2017a). Regarding genes related to the stress response, 14 out of 20 were downregulated, 439 including heme oxygenase enzymes ( $\operatorname{mox} 1, h m o x 2 a$ and $h m \times 2 b)$ responsible to protect cells 440 from oxidative stress, and usually upregulated by exposure to acute stress (Poss \& Tonegawa, 441 1997). There were also changes in five genes of the heat-shock protein family, chaperones that 442 play important roles in the cellular stress response (Parsell \& Lindquist, 1993); three were 443 downregulated (hsp13, hsp14 hspa9, hspb8) and two upregulated (hsp14 and hsp90aal.1). The 444 hsp90aa1.1, is a crucial gene for cortisol activity since it is a GR cofactor (Pratt, 1997). In the 445 rare minnow (Gobiocypris rarus), hsp90aal.1 was upregulated in the hepatopancreas, gills and 446 intestine when subjected to high doses of cadmium (Liu et al., 2017). In European sea bass 447 exposed to chronic confinement stress hsp90aal.1 was downregulated in brain but not in liver 448 (Gornati et al., 2004). This variability in gene expression may reflect not only tissue-specific 449 stress responses but also species-specific differences in responses to acute $v s$. chronic stress 450 (Pottinger, 2008). 
452 The comparison of the ovarian transcriptomes of females exposed to either elevated population

453 density or temperature allows insights into what are the conserved signatures irrespective of type

454 of perturbation. It is difficult to say whether zebrafish gonads are more sensitive to elevated

455 temperature or elevated rearing density because a proper estimation would require carefully

456 designed dose-response experiments and comparing, for example, the transcriptomes of females

457 when, say, $50 \%$ of the initial females become masculinized either after temperature or density,

458 which is not the case in this study. However, at least it is interesting to notice a certain

459 relationship between the degree of masculinization and the average fold change of genes

460 commonly affected by both factors (temperature $>$ density).

461

462 Of the 1,269 DEGs shared in both type of perturbations, 373 DEGs were affected in the same

463 direction regardless of environmental perturbation. Among these common genes, faima was

464 strongly upregulated $(\mathrm{FC}=14.07$ and 4.78 in density and temperature experiments, respectively).

465 Faima is an inhibitor of the apoptotic response and it is expressed in mammalian ovaries during

466 follicular atresia in the granulosa cells (Matsuda-Minehata et al., 2006) having similar expression

467 pattern to that of foxl2 gene in the ovaries (Nikic \& Vaiman, 2004). During sex differentiation,

468 juvenile zebrafish ovaries activate apoptotic pathways and, although further research is needed,

469 faima could play a role in the resistance to masculinization and, therefore, could be a potential

470 maker for those females that although subjected to environmental perturbations they still manage

471 to develop ovaries. Ptpdc1, upregulated in fish ovaries by elevated density and temperature

472 exposure $(\mathrm{FC}=8.64$ and 4.59 , respectively), is a pleiotropic gene that regulates a variety of

473 cellular processes including cellular growth and differentiation (Bonetti et al., 2014). Other

474 examples of common upregulated genes were: $c \mathrm{~cm} 2 l$, involved in malformation in heart and body

475 axis in zebrafish (Cullere et al., 2015) and ankrd6b, which phosphorylates and inhibits the beta- 
476 catenin signal during zebrafish development (Moeller et al., 2006). Among those downregulated 477 genes, we found lgals9l1 (FC temperature $=-9.21$ and density $=-2.85$ ), which belongs to the 478 galectin protein family and is implicated in modulating cell-cell and cell-matrix interactions and 479 its associated with immunodeficiency diseases in humans (Mengshol et al., 2010). In zebrafish, 480 its expression was identified in larva coping with viral RNA infection (Briolat et al., 2014). We 481 also found $u b x n 2 a$, which in humans is involved in apoptosis by activating the p53 signaling 482 pathway (Sane et al., 2014) and interacts with spata5 gene during spermatogenesis (Hein et al., 483 2015). Regarding canonical reproduction-related genes in the common lists, both stressors 484 downregulated the expression of cyp 19ala and upregulated amh and sycp3 in the ovaries of non485 masculinized females. It is known that during the gonadal development process in zebrafish, 486 testis development requires an upregulation of amh together with a downregulation of cyp 19ala 487 in the immature ovary (Wang \& Orban, 2007). Thus, regardless of the exposure some females 488 resisted masculinization even though their amh levels were upregulated in the mature ovary. The 489 fact that the upregulation of some pro-male genes and pathways was also observed in ovaries of 490 zebrafish treated with a demethylation agent (decitabine) during sex differentiation, which 491 skewed sex ratios towards females (Ribas et al., 2017d), may indicate that activation of some pro492 male genes is consequence of the presence of external disturbances during sex differentiation 493 rather than the masculinization per se brought by these perturbations. The results presented here, 494 open the possibility that these well-known reproduction-related genes, cyp19ala, amh and sycp3, 495 but also other genes with other functions such as faima, ccm2l, ankrd6b, lgals9l1 or ubxn2a, 496 might be good markers of environmental perturbation independent of conspicuous alterations in 497 sex ratios or gonadal morphology. 
499 The 373 DEGs affected in the same direction regardless of environmental perturbation yield a

500 total of $17 \mathrm{GO}$ terms. Most of these were related to cellular and metabolic processes, suggesting

501 that the biosynthesis of some compounds were affected. In particular, we found a downregulation

502 of the methylation GO-term which is known to be involved in sex differentiation in fish

503 (Navarro-Martín et al., 2011; Anastasiadi et al., 2017). This GO-included the RNA (guanine-7-)

504 methyltransferase ( $r n m t)$, histamine $\mathrm{N}$-methyltransferase ( $\mathrm{hnmt}$ ) and suv420h2 genes, which are

505 three metyltransferases that regulate the epigenome of developing organs and of the germline

506 (Anway et al., 2008) and their dysfunction is involved in multiple human diseases (García-Martín

507 et al., 2010). It also contained two more genes: the enhancer of zeste 2 polycomb repressive

508 complex 2 subunitgene (ezh2), involved in maintaining the transcriptional repressive state of

509 certain genes and the regulation of male germ cell development in mice (Mu et al., 2017), and the

510 SET domain containing $3(\operatorname{setd} 3)$ gene, which acts as a transcriptional activator of histone H3K36

511 (Kim et al., 2011).

512

513 There were no significant common KEGG pathways from the 373 DEGs after exposure to either

514 elevated temperature or density. However, comparison of the KEGG pathways significantly

515 affected by elevated density with those affected by elevated temperature showed that there were a

516 total of five significant KEGG pathways in which the gonadotropin-releasing hormone receptor

517 (GnRHr) pathway was activated. GnRH stimulates the secretion of luteinizing hormone (LH) and

518 follicle-stimulating hormone (FSH), both acting synergistically in the reproductive system

519 (Millar, 2005), and in the seabream was observed that GnRH plays an important role in the

520 regulation of gonadal differentiation preventing the regression towards the testis from the ovary

521 (Soverchia et al., 2007). In contrast, inflammation mediated by chemokine and cytokine, integrin

522 signalling and angiogenesis pathways were inhibited. These pathways are involved in protective 
523 response of cells to pathogens, infection or tissue damage, as observed in zebrafish larvae

524 exposed to pathogens (Díaz-Pascual et al., 2017). Interestingly, these pathways are also activated 525 during ovarian commitment in zebrafish sex differentiation, an inflammatory response process

526 where the activation of NF- $\kappa \beta$ and Wnt signalling pathways are required (Liew \& Orbán, 2013).

528 Conclusion

529 Previously, we had shown that exposure of zebrafish to constant elevated population density since 530 early life masculinized some females. In the present study, we show that it also delayed gonadal 531 maturation in both sexes and, further, that resistant females had a gonadal transcriptome similar in 532 many ways to the transcriptome of females resistant to the masculinizing effects of elevated 533 temperature. These transcriptomic changes include the upregulation of some known pro-male 534 genes such as amh, sycp3 and spata6, but also of other novel genes not previously related to 535 reproduction, such as faima, ccm $2 l$, ankrd6b. Commonly downregulated genes include lgals9ll, $536 u b x n 2 a$ genes in addition to cyp19a1a. These persistent gene expression changes can be used as 537 markers indicative of previous exposure to environmental perturbations of both biotic and abiotic 538 origin present in fish with otherwise apparently normal fish ovaries. If conserved in other species, 539 these markers could be used in the assessment of hidden effects of environmental stress, although 540 it remains to be determined the actual consequences in terms of reproduction in affected females. 541

\section{Acknowledgements}

543 This study was supported by MINECO grants AGL2016-787107-R "Epimark" to FP and

544 AGL2015-73864-JIN “Ambisex” to LR. We thank Sílvia Joly for technical assistance. 545 


\section{Conflict of interest}

547 The authors declare that there is no conflict of interest.

548

549

550

551

552

553

554

555

556

557

558

559

560

561

562

563

564

565

566

567

568

569

570

571

572

573

574

575

576

577

578

579

580

581

582

583

584

585

586

587

\section{References}

Abozaid, H., Wessels, S., \& Horstgen-Schwark, G. (2012). Elevated temperature applied during gonadal transformation leads to male bias in zebrafish (Danio rerio). Sexual Development, 6, 201-209. doi:10.1159/000336297

Alsop, D., Ings, J. S., \& Vijayan, M. M. (2009). Adrenocorticotropic hormone suppresses gonadotropin-stimulated estradiol release from zebrafish ovarian follicles. PLoS One, 4, e6463.

Alsop, D., \& Vijayan, M. M. (2008). Development of the corticosteroid stress axis and receptor expression in zebrafish. American Journal of Physiology-Regulatory, Integrative and Comparative Physiology, 294, R711-R719. doi:10.1152/ajpregu.00671.2007

Anastasiadi, D., Díaz, N., \& Piferrer, F. (2017). Small ocean temperature increases elicit stagedependent changes in DNA methylation and gene expression in a fish, the European sea bass. Scientific reports, 7, 12401. doi:10.1038/s41598-017-10861-6

Anway, M. D., Rekow, S. S., \& Skinner, M. K. (2008). Transgenerational epigenetic programming of the embryonic testis transcriptome. Genomics, 91, 30-40. doi:10.1016/j.ygeno.2007.10.002

Baras, E., Jacobs, B., \& Mélard, C. (2001). Effect of water temperature on survival, growth and phenotypic sex of mixed (XX-XY) progenies of Nile tilapia Oreochromis niloticus. Aquaculture, 192, 187-199. doi:10.1016/S0044-8486(00)00452-X

Baroiller, J. F., \& D'Cotta, H. (2016). The reversible sex of Gonochoristic fish: insights and consequences. Sexual Development, 10, 242-266. doi:10.1159/000452362

Barton, B. A., Ribas, L., Acerete, L., \& Tort, L. (2005). Effects of chronic confinement on physiological responses of juvenile gilthead sea bream, Sparus aurata L., to acute handling. Aquaculture Research, 36, 172-179. doi:10.1111/j.1365-2109.2004.01202.x

Beck, I. M., Vanden Berghe, W., Vermeulen, L., Yamamoto, K. R., Haegeman, G., \& De Bosscher, K. (2009). Crosstalk in inflammation: the interplay of glucocorticoid receptorbased mechanisms and kinases and phosphatases. Endocrine reviews, 30, 830-882. doi:10.1210/er.2009-0013

Bonetti, M., Rodriguez-Martinez, V., Overman, J. P., Overvoorde, J., van Eekelen, M., Jopling, C., \& den Hertog, J. (2014). Distinct and overlapping functions of ptpn11 genes in zebrafish development. PLoS One, 9, e94884. doi:10.1371/journal.pone.0094884

Bonga, S. E. W. (1997). The stress response in fish. Physiological Reviews, 77, 591-625. doi:10.1152/physrev.1997.77.3.591

Briolat, V., Jouneau, L., Carvalho, R., Palha, N., Langevin, C., Herbomel, P., . . Boudinot, P. (2014). Contrasted innate responses to two viruses in zebrafish: insights into the ancestral repertoire of vertebrate IFN-stimulated genes. The Journal of Immunology, 1302611. doi:10.4049/jimmunol.1302611

Brown, A. R., Owen, S. F., Peters, J., Zhang, Y., Soffker, M., Paull, G. C., . . Tyler, C. R. (2015). Climate change and pollution speed declines in zebrafish populations. 
588

589

590

591

592

593

594

595

596

597

598

599

600

601

602

603

604

605

606

607

608

609

610

611

612

613

614

615

616

617

618

619

620

621

622

623

624

625

626

627

628

629

630

631

632

633

634

Proceedings of the National Academy of Sciences, 112, E1237-1246.

doi:10.1073/pnas.1416269112

Cullere, X., Plovie, E., Bennett, P. M., MacRae, C. A., \& Mayadas, T. N. (2015). The cerebral cavernous malformation proteins CCM2L and CCM2 prevent the activation of the MAP kinase MEKK3. Proceedings of the National Academy of Sciences, 112, 14284-14289. doi:10.1073/pnas.1510495112

de Castro Assis, L. H., de Nóbrega, R. H., Gómez-González, N. E., Bogerd, J., \& Schulz, R. W. (2018). Estrogen-induced inhibition of spermatogenesis in zebrafish is largely reversed by androgen. Journal of Molecular Endocrinology, 60, 273-284. doi:10.1530/JME-17-0177

Devlin, R. H., \& Nagahama, Y. (2002). Sex determination and sex differentiation in fish: an overview of genetic, physiological, and environmental influences. Aquaculture, 208, 191364. doi:10.1016/S0044-8486(02)00057-1

Díaz-Pascual, F., Ortíz-Severín, J., Varas, M. A., Allende, M. L., \& Chávez, F. P. (2017). In vivo host-pathogen interaction as revealed by global proteomic profiling of zebrafish larvae. Frontiers in cellular and infection microbiology, 7, 334. doi: 10.3389/fcimb.2017.00334

Diaz, N., \& Piferrer, F. (2015). Lasting effects of early exposure to temperature on the gonadal transcriptome at the time of sex differentiation in the European sea bass, a fish with mixed genetic and environmental sex determination. BMC Genomics, 16, 679. doi:10.1186/s12864-015-1862-0

Eissa, N., \& Wang, H. P. (2016). Transcriptional stress responses to environmental and husbandry stressors in aquaculture species. Reviews in Aquaculture, 8, 61-88. doi:10.1111/raq.12081

Fan, Z., You, F., Wang, L., Weng, S., Wu, Z., Hu, J., . . Zhang, P. (2014). Gonadal transcriptome analysis of male and female olive flounder (Paralichthys olivaceus). BioMed research international, 2014. doi:10.1155/2014/291067

Fernandino, J. I., Hattori, R. S., Kishii, A., Strussmann, C. A., \& Somoza, G. M. (2012). The cortisol and androgen pathways cross talk in high temperature-induced masculinization: the 11 beta-hydroxysteroid dehydrogenase as a key enzyme. Endocrinology, 153, 60036011. doi:10.1210/en.2012-1517

Fernandino, J. I., Hattori, R. S., Moreno Acosta, O. D., Strussmann, C. A., \& Somoza, G. M. (2013). Environmental stress-induced testis differentiation: androgen as a by-product of cortisol inactivation. General and comparative endocrinology, 192, 36-44. doi:10.1016/j.ygcen.2013.05.024

Francis, R. C. (1984). The effects of bidirectional selection for social dominance on agonistic behavior and sex ratios in the paradise fish (Macropodus opercularis). Behaviour, 90, 2544. doi:10.1163/156853984X00542

García-Martín, E., Martínez, C., Benito-León, J., Calleja, P., Díaz-Sánchez, M., Pisa, D., . . . Agúndez, J. (2010). Histamine-N-methyl transferase polymorphism and risk for multiple sclerosis. European journal of neurology, 17, 335-338. doi:10.1111/j.14681331.2009.02720.x

Gornati, R., Terova, G., Vigetti, D., Prati, M., Saroglia, M., \& Bernardini, G. (2004). Effects of population density on seabass (Dicentrarchus labrax, L.) gene expression. Aquaculture, 230, 229-239.

Hattori, R. S., Fernandino, J. I., Kishii, A., Kimura, H., Kinno, T., Oura, M., . . Watanabe, S. (2009). Cortisol-induced masculinization: does thermal stress affect gonadal fate in pejerrey, a teleost fish with temperature-dependent sex determination? PLoS One, 4, e6548. doi:10.1371/journal.pone. 0006548 
635

636

637

638

639

640

641

642

643

644

645

646

647

648

649

650

651

652

653

654

655

656

657

658

659

660

661

662

663

664

665

666

667

668

669

670

671

672

673

674

675

676

677

678

679

680

681
Hein, M. Y., Hubner, N. C., Poser, I., Cox, J., Nagaraj, N., Toyoda, Y., . . Buchholz, F. (2015). A human interactome in three quantitative dimensions organized by stoichiometries and abundances. Cell, 163, 712-723. doi:10.1016/j.cell.2015.09.053

Herrera, M., Ruiz-Jarabo, I., Vargas-Chacoff, L., la Roca, E., \& Mancera, J. M. (2015). Metabolic enzyme activities in relation to crowding stress in the wedge sole (Dicologoglossa cuneata). Aquaculture Research, 46, 2808-2818. doi:10.1111/are.12440

Heule, C., Salzburger, W., \& Böhne, A. (2014). Genetics of sexual development: an evolutionary playground for fish. Genetics, 196, 579-591. doi:10.1534/genetics.114.161158

Hliwa, P., Bah, M., Kuźmiński, H., Dobosz, S., \& Ciereszko, A. (2013). Ultrasound evaluation of the gonadal structure in sex-reversed rainbow trout females. Aquaculture International, 22, 89-96. doi:10.1007/s10499-013-9646-5

Huang Da, W., Sherman, B. T., \& Lempicki, R. A. (2009a). Bioinformatics enrichment tools: paths toward the comprehensive functional analysis of large gene lists. Nucleic acids research, 37, 1-13. doi:10.1093/nar/gkn923

Huang Da, W., Sherman, B. T., \& Lempicki, R. A. (2009b). Systematic and integrative analysis of large gene lists using DAVID bioinformatics resources. Nature protocols, 4, 44-57. doi:10.1038/nprot.2008.211

Huertas, M., \& Cerdà, J. (2006). Stocking density at early developmental stages affects growth and sex ratio in the European eel (Anguilla anguilla). The Biological Bulletin, 211, 286296. doi: $10.2307 / 4134550$

Kiilerich, P., Servili, A., Peron, S., Valotaire, C., Goardon, L., Leguen, I., \& Prunet, P. (2018). Regulation of the corticosteroid signalling system in rainbow trout HPI axis during confinement stress. General and comparative endocrinology, 258, 184-193. doi:10.1016/j.ygcen.2017.08.013

Kiilerich, P., Servili, A., Péron, S., Valotaire, C., Goardon, L., Leguen, I., \& Prunet, P. (2017). Regulation of the corticosteroid signalling system in rainbow trout HPI axis during confinement stress. General and comparative endocrinology. doi:10.1016/j.ygcen.2017.08.013

Kim, D. W., Kim, K. B., Kim, J. Y., \& Seo, S. B. (2011). Characterization of a novel histone H3K36 methyltransferase setd3 in zebrafish. Bioscience, biotechnology, and biochemistry, 75, 289-294. doi:10.1271/bbb.100648

Kitano, T., Takamune, K., Kobayashi, T., Nagahama, Y., \& Abe, S. (1999). Suppression of P450 aromatase gene expression in sex-reversed males produced by rearing genetically female larvae at a high water temperature during a period of sex differentiation in the Japanese flounder (Paralichthys olivaceus). Journal of Molecular Endocrinology, 23, 167-176. doi:10.1677/jme.0.0230167

Lau, E. S., Zhang, Z., Qin, M., \& Ge, W. (2016). Knockout of zebrafish ovarian aromatase gene (cyp19a1a) by TALEN and CRISPR/Cas9 leads to all-male offspring due to failed ovarian differentiation. Scientific reports, 6, 37357. doi:10.1038/srep37357

Le, P. P., Friedman, J. R., Schug, J., Brestelli, J. E., Parker, J. B., Bochkis, I. M., \& Kaestner, K. H. (2005). Glucocorticoid receptor-dependent gene regulatory networks. PLoS genetics, 1, e16. doi:10.1371/journal.pgen.0010016

Liew, W. C., Bartfai, R., Lim, Z., Sreenivasan, R., Siegfried, K. R., \& Orban, L. (2012). Polygenic sex determination system in zebrafish. PLoS One, 7, e34397. doi:10.1371/journal.pone.0034397

Liew, W. C., \& Orbán, L. (2013). Zebrafish sex: a complicated affair. Briefings in functional genomics, 13, 172-187. doi:10.1093/bfgp/elt041 
682

683

684

685

686

687

688

689

690

691

692

693

694

695

696

697

698

699

700

701

702

703

704

705

706

707

708

709

710

711

712

713

714

715

716

717

718

719

720

721

722

723

724

725

726

727
Liu, X., Wang, Z., Jin, L., Huang, J., Pu, D. Y., Wang, D. S., \& Zhang, Y. G. (2017). Effects of subchronic exposure to waterborne cadmium on HPI axis hormones and related genes in rare minnows (Gobiocypris rarus). Comparative Biochemistry and Physiology Part C: Toxicology \& Pharmacology, 202, 1-11. doi:10.1016/j.cbpc.2017.07.002

Livak, K. J., \& Schmittgen, T. D. (2001). Analysis of relative gene expression data using realtime quantitative PCR and the $2-\Delta \Delta \mathrm{CT}$ method. Methods, 25, 402-408. doi:10.1006/meth.2001.1262

Lu, J., Luan, P., Zhang, X., Xue, S., Peng, L., Mahbooband, S., \& Sun, X. (2014). Gonadal transcriptomic analysis of yellow catfish (Pelteobagrus fulvidraco): identification of sexrelated genes and genetic markers. Physiological genomics, 46, 798-807. doi:10.1152/physiolgenomics.00088.2014

Matsuda-Minehata, F., Inoue, N., Goto, Y., \& Manabe, N. (2006). The regulation of ovarian granulosa cell death by pro-and anti-apoptotic molecules. Journal of Reproduction and Development, 52, 695-705. doi:10.1262/jrd.18069

McCurley, A. T., \& Callard, G. V. (2008). Characterization of housekeeping genes in zebrafish: male-female differences and effects of tissue type, developmental stage and chemical treatment. BMC molecular biology, 9, 102. doi:10.1186/1471-2199-9-102

Mengshol, J. A., Golden-Mason, L., Arikawa, T., Smith, M., Niki, T., McWilliams, R., .. . Rangachari, M. (2010). Correction: A Crucial Role for Kupffer Cell-Derived Galectin-9 in Regulation of T Cell Immunity in Hepatitis C Infection. PLoS One, 5. doi:10.1371/annotation/d15b793c-85c7-4529-bc80-aabcb088a8cf

Millar, R. P. (2005). GnRHs and GnRH receptors. Animal reproduction science, 88, 5-28. doi:10.1016/j.anireprosci.2005.05.032

Moeller, H., Jenny, A., Schaeffer, H. J., Schwarz-Romond, T., Mlodzik, M., Hammerschmidt, M., \& Birchmeier, W. (2006). Diversin regulates heart formation and gastrulation movements in development. Proceedings of the National Academy of Sciences, 103, 15900-15905. doi:10.1073/pnas.0603808103

Mu, W., Starmer, J., Shibata, Y., Yee, D., \& Magnuson, T. (2017). EZH1 in germ cells safeguards the function of PRC2 during spermatogenesis. Developmental biology, 424, 198-207. doi:10.1016/j.ydbio.2017.02.017

Navarro-Martín, L., Viñas, J., Ribas, L., Díaz, N., Gutiérrez, A., Di Croce, L., \& Piferrer, F. (2011). DNA methylation of the gonadal aromatase (cyp19a) promoter is involved in temperature-dependent sex ratio shifts in the European sea bass. PLoS genetics, 7, e1002447. doi:doi.org/10.1371/journal.pgen.1002447

Nikic, S., \& Vaiman, D. (2004). Conserved patterns of gene expression in mice and goats in the vicinity of the Polled Intersex Syndrome (PIS) locus. Chromosome research, 12, 465-474. doi:10.1023/B:CHRO.0000034746.46789.e0

Orban, L., Sreenivasan, R., \& Olsson, P. E. (2009). Long and winding roads: testis differentiation in zebrafish. Molecular and cellular endocrinology, 312, 35-41.

doi:10.1016/j.mce.2009.04.014

Ospina-Alvarez, N., \& Piferrer, F. (2008). Temperature-dependent sex determination in fish revisited: prevalence, a single sex ratio response pattern, and possible effects of climate change. PLoS One, 3, e2837. doi:10.1371/journal.pone.0002837

Ozaki, Y., Saito, K., Shinya, M., Kawasaki, T., \& Sakai, N. (2011). Evaluation of Sycp3, Plzf and Cyclin B3 expression and suitability as spermatogonia and spermatocyte markers in zebrafish. Gene Expression Patterns, 11, 309-315. doi:10.1016/j.gep.2011.03.002 
728

729

730

731

732

733

734

735

736

737

738

739

740

741

742

743

744

745

746

747

748

749

750

751

752

753

754

755

756

757

758

759

760

761

762

763

764

765

766

767

768

769

770

771

772

773

Pandian, T., \& Sheela, S. (1995). Hormonal induction of sex reversal in fish. Aquaculture, 138, 1-22. doi:10.1016/0044-8486(95)01075-0

Parsell, D. A., \& Lindquist, S. (1993). The function of heat-shock proteins in stress tolerance: degradation and reactivation of damaged proteins. Annual Review of Genetics, 27, 437496. doi:10.1146/annurev.ge.27.120193.002253

Penman, D. J., \& Piferrer, F. (2008). Fish gonadogenesis. Part I: genetic and environmental mechanisms of sex determination. Reviews in Fisheries Science, 16, 16-34. doi:10.1080/10641260802324610

Piato, Â. L., Capiotti, K. M., Tamborski, A. R., Oses, J. P., Barcellos, L. J., Bogo, M. R., . . Bonan, C. D. (2011). Unpredictable chronic stress model in zebrafish (Danio rerio): behavioral and physiological responses. Progress in Neuro-Psychopharmacology and Biological Psychiatry, 35, 561-567. doi:10.1016/j.pnpbp.2010.12.018

Piferrer, F. (2001). Endocrine sex control strategies for the feminization of teleost fish. In Reproductive Biotechnology in Finfish Aquaculture (pp. 229-281): Elsevier.

Piferrer, F. (2018). La determinació del sexe. Atzavara, L', 28, 39-60.

Poss, K. D., \& Tonegawa, S. (1997). Reduced stress defense in heme oxygenase 1-deficient cells. Proceedings of the National Academy of Sciences, 94, 10925-10930.

Pottinger, T. G. (2008). The stress response in fish-mechanisms, effects and measurement. Fish Welfare. Blackwell Publishing Ltd, UK, 32-48.

Pratt, W. B. (1997). The role of the hsp90-based chaperone system in signal transduction by nuclear receptors and receptors signaling via map kinase. Annual Review of Pharmacology and Toxicology, 37, 297-326. doi:10.1146/annurev.pharmtox.37.1.297

Ramsay, J. M., Feist, G. W., Varga, Z. M., Westerfield, M., Kent, M. L., \& Schreck, C. B. (2006). Whole-body cortisol is an indicator of crowding stress in adult zebrafish, Danio rerio. Aquaculture, 258, 565-574. doi:10.1016/j.aquaculture.2006.04.020

Ramsay, J. M., Feist, G. W., Varga, Z. M., Westerfield, M., Kent, M. L., \& Schreck, C. B. (2009). Whole-body cortisol response of zebrafish to acute net handling stress. Aquaculture, 297, 157-162. doi:10.1016/j.aquaculture.2009.08.035

Ribas, L., Liew, W. C., Diaz, N., Sreenivasan, R., Orban, L., \& Piferrer, F. (2017a). Heat-induced masculinization in domesticated zebrafish is family-specific and yields a set of different gonadal transcriptomes. Proceedings of the National Academy of Sciences, 114, E941E950. doi:10.1073/pnas.1609411114

Ribas, L., Valdivieso, A., Diaz, N., \& Piferrer, F. (2017b). Appropriate rearing density in domesticated zebrafish to avoid masculinization: links with the stress response. Journal of Experimental Biology, 220, 1056-1064. doi:10.1242/jeb.144980

Ribas, L., Valdivieso, A., Diaz, N., \& Piferrer, F. (2017c). Response to "The importance of controlling genetic variation - remarks on 'Appropriate rearing density in domesticated zebrafish to avoid masculinization: links with the stress response'". Journal of Experimental Biology, 220, 4079-4080. doi:10.1242/jeb.167437

Ribas, L., Vanezis, K., Imués, M., \& Piferrer, F. (2017d). Treatment with a DNA methyltransferase inhibitor feminizes zebrafish and induces long-term expression changes in the gonads. Epigenetics \& chromatin, 10, 59. doi:10.1186/s13072-017-0168-7

Rodriguez-Mari, A., Yan, Y. L., Bremiller, R. A., Wilson, C., Canestro, C., \& Postlethwait, J. H. (2005). Characterization and expression pattern of zebrafish Anti-Mullerian hormone (Amh) relative to sox9a, sox9b, and cyp19ala, during gonad development. Gene Expression Patterns, 5, 655-667. doi:10.1016/j.modgep.2005.02.008 
774

775

776

777

778

779

780

781

782

783

784

785

786

787

788

789

790

791

792

793

794

795

796

797

798

799

800

801

802

803

804

805

806

807

808

809

810

811

812

813

814

815

816

817

818

819
Roncarati, A., Melotti, P., Mordenti, O., \& Gennari, L. (1997). Influence of stocking density of European eel (Anguilla anguilla, L.) elvers on sex differentiation and zootechnical performances. Journal of Applied Ichthyology, 13, 131-136. doi:10.1111/j.14390426.1997.tb00112.x

Saillant, E., Fostier, A., Haffray, P., Menu, B., Laureau, S., Thimonier, J., \& Chatain, B. (2003). Effects of rearing density, size grading and parental factors on sex ratios of the sea bass (Dicentrarchus labrax L.) in intensive aquaculture. Aquaculture, 221, 183-206. doi:10.1016/s0044-8486(02)00539-2

Saillant, E., Fostier, A., Haffray, P., Menu, B., Thimonier, J., \& Chatain, B. (2002). Temperature effects and genotype-temperature interactions on sex determination in the European sea bass (Dicentrarchus labrax L.). Journal of Experimental Zoology Part A: Ecological Genetics and Physiology, 292, 494-505. doi:10.1534/genetics.114.161158

Saito, K., Siegfried, K. R., Nüsslein-Volhard, C., \& Sakai, N. (2011). Isolation and cytogenetic characterization of zebrafish meiotic prophase I mutants. Developmental Dynamics, 240, 1779-1792. doi:10.1002/dvdy.22661

Sane, S., Abdullah, A., Boudreau, D., Autenried, R., Gupta, B., Wang, X., .. . Telleria, C. (2014). Ubiquitin-like (UBX)-domain-containing protein, UBXN2A, promotes cell death by interfering with the p53-Mortalin interactions in colon cancer cells. Cell death \& disease, 5, e1118. doi:10.1038/cddis.2014.100

Sarre, S. D., Georges, A., \& Quinn, A. (2004). The ends of a continuum: genetic and temperature-dependent sex determination in reptiles. Bioessays, 26, 639-645. doi: $10.1002 /$ bies. 20050

Schartl, M. (2004). Sex chromosome evolution in non-mammalian vertebrates. Current opinion in genetics \& development, 14, 634-641. doi:10.1016/j.gde.2004.09.005

Schreck, C. B. (2010). Stress and fish reproduction: the roles of allostasis and hormesis. General and comparative endocrinology, 165, 549-556. doi:10.1016/j.ygcen.2009.07.004

Shang, E. H., Yu, R. M., \& Wu, R. S. (2006). Hypoxia affects sex differentiation and development, leading to a male-dominated population in zebrafish (Danio rerio). Environmental science \& technology, 40, 3118-3122.

Small, C. M., Carney, G. E., Mo, Q., Vannucci, M., \& Jones, A. G. (2009). A microarray analysis of sex- and gonad-biased gene expression in the zebrafish: evidence for masculinization of the transcriptome. BMC Genomics, 10, 579. doi:10.1186/1471-2164-10-579

Smyth, G. K., \& Speed, T. (2003). Normalization of cDNA microarray data. Methods, 31, 265273. doi:10.1016/s1046-2023(03)00155-5

Soverchia, L., Carotti, M., Andreu-Vieyra, C., Mosconi, G., Cannella, N., Habibi, H., \& Polzonetti-Magni, A. (2007). Role of gonadotropin-releasing hormone (GnRH) in the regulation of gonadal differentiation in the gilthead seabream (Sparus aurata). Molecular Reproduction and Development: Incorporating Gamete Research, 74, 57-67. doi:10.1002/mrd.20484

Sreenivasan, R., Cai, M., Bartfai, R., Wang, X., Christoffels, A., \& Orban, L. (2008). Transcriptomic analyses reveal novel genes with sexually dimorphic expression in the zebrafish gonad and brain. PLoS One, 3, e1791. doi:10.1371/journal.pone.0001791

Sun, L. X., Teng, J., Zhao, Y., Li, N., Wang, H., \& Ji, X. S. (2018). Gonad Transcriptome Analysis of High-Temperature-Treated Females and High-Temperature-Induced SexReversed Neomales in Nile Tilapia. International journal of molecular sciences, 19, 689. doi:10.3390/ijms 19030689 
Supek, F., Bosnjak, M., Skunca, N., \& Smuc, T. (2011). REVIGO summarizes and visualizes long lists of gene ontology terms. PLoS One, 6, e21800.

doi:10.1371/journal.pone.0021800

822

823

824

825

826

827

828

829

830

831

832

833

834

835

836

837

838

839

840

841

842

843

844

845

846

847

848

849

850

851

852

853

854

855

856

857

858

859

860

861

862

863

864

Sutton, E., Hughes, J., White, S., Sekido, R., Tan, J., Arboleda, V., . . Thomas, P. (2011). Identification of SOX3 as an XX male sex reversal gene in mice and humans. Journal of clinical investigation, 121, 328-341. doi:10.1172/JCI42580

Takashi, H. (1977). Juvenile hermaphroditism in the zebrafish, Brachydanio rerio. 北海道大學水 産學部研究彙報=BULLETIN OF THE FACULTY OF FISHERIES HOKKAIDO UNIVERSITY, 28, 57-65.

Team, R. C. (2013). R: A language and environment for statistical computing.

Uchida, D., Yamashita, M., Kitano, T., \& Iguchi, T. (2002). Oocyte apoptosis during the transition from ovary-like tissue to testes during sex differentiation of juvenile zebrafish. Journal of Experimental Biology, 205, 711-718.

Uchida, D., Yamashita, M., Kitano, T., \& Iguchi, T. (2004). An aromatase inhibitor or high water temperature induce oocyte apoptosis and depletion of $\mathrm{P} 450$ aromatase activity in the gonads of genetic female zebrafish during sex-reversal. Comparative Biochemistry and Physiology Part A: Molecular \& Integrative Physiology, 137, 11-20. doi:10.1016/s10956433(03)00178-8

Valdivia, K., Jouanno, E., Volff, J. N., Galiana-Arnoux, D., Guyomard, R., Helary, L., . . . Guiguen, Y. (2014). High temperature increases the masculinization rate of the all-female (XX) rainbow trout "Mal" population. PLoS One, 9, e113355. doi:10.1371/journal.pone.0113355

Valenzuela, N. (2008). Sexual development and the evolution of sex determination. Sexual Development, 2, 64-72. doi:10.1159/000129691

Valenzuela, N., \& Lance, V. (2004). Temperature-dependent sex determination in vertebrates: Smithsonian Books Washington, DC.

Vandeputte, M., Dupont-Nivet, M., Chavanne, H., \& Chatain, B. (2007). A polygenic hypothesis for sex determination in the European sea bass Dicentrarchus labrax. Genetics, 176, 10491057. doi:10.1534/genetics.107.072140

von Hofsten, J., \& Olsson, P. E. (2005). Zebrafish sex determination and differentiation: involvement of FTZ-F1 genes. Reproductive Biology and Endocrinology, 3, 63. doi:10.1186/1477-7827-3-63

Wang, D. S., Kobayashi, T., Zhou, L.-Y., Paul-Prasanth, B., Ijiri, S., Sakai, F., . . Nagahama, Y. (2007). Fox12 up-regulates aromatase gene transcription in a female-specific manner by binding to the promoter as well as interacting with ad4 binding protein/steroidogenic factor 1. Molecular Endocrinology, 21, 712-725.

Wang, X. G., \& Orban, L. (2007). Anti-Mullerian hormone and 11 beta-hydroxylase show reciprocal expression to that of aromatase in the transforming gonad of zebrafish males. Developmental Dynamics, 236, 1329-1338. doi:10.1002/dvdy.21129

Webster, K. A., Schach, U., Ordaz, A., Steinfeld, J. S., Draper, B. W., \& Siegfried, K. R. (2017). Dmrt1 is necessary for male sexual development in zebrafish. Developmental biology, 422, 33-46. doi:10.1016/j.ydbio.2016.12.008

Wilhelm, D., \& Englert, C. (2002). The Wilms tumor suppressor WT1 regulates early gonad development by activation of Sf1. Genes \& Development, 16, 1839-1851. doi:10.1101/gad.220102 
865 Wilson, C. A., High, S. K., McCluskey, B. M., Amores, A., Yan, Y. L., Titus, T. A., ... Postlethwait, J. H. (2014). Wild sex in zebrafish: loss of the natural sex determinant in domesticated strains. Genetics, 198, 1291-1308. doi:10.1534/genetics.114.169284

Yamamoto, Y., Zhang, Y., Sarida, M., Hattori, R. S., \& Strüssmann, C. A. (2014). Coexistence of genotypic and temperature-dependent sex determination in pejerrey Odontesthes bonariensis. PLoS One, 9, e102574. doi: 10.1371/journal.pone.0102574

Yang, Y. J., Wang, Y., Li, Z., Zhou, L., \& Gui, J. F. (2017). Sequential, divergent, and cooperative requirements of foxl2a and foxl2b in ovary development and maintenance of zebrafish. Genetics, 205, 1551-1572.

Yeh, C. M., Glöck, M., \& Ryu, S. (2013). An optimized whole-body cortisol quantification method for assessing stress levels in larval zebrafish. PLoS One, 8, e79406. doi:10.1371/journal.pone.0079406

Yuan, S., Stratton, C. J., Bao, J., Zheng, H., Bhetwal, B. P., Yanagimachi, R., \& Yan, W. (2015). Spata6 is required for normal assembly of the sperm connecting piece and tight head-tail conjunction. Proceedings of the National Academy of Sciences, 112, E430-439.

881

882

883

884

885

886

887

888

889

890

891

892 
893 Table 1. Top ten up- and downregulated genes in the set A and D of genes commonly expressed in ovaries of females exposed to

894 elevated density or temperature

\begin{tabular}{|c|c|c|c|c|c|}
\hline Set & Gene name & Gene symbol & Ref. seq & $\begin{array}{l}\text { Density } \\
\text { fold } \\
\text { change }\end{array}$ & $\begin{array}{l}\text { Temperature } \\
\text { fold change }\end{array}$ \\
\hline \multirow[t]{7}{*}{ A } & fas apoptotic inhibitory molecule a & faima & NM_001002583 & 14.07 & 4.78 \\
\hline & cerebral cavernous malformation 2-like & $\operatorname{ccm} 2 l$ & XM_692004 & 8.39 & 3.88 \\
\hline & adenylate kinase $7 b$ & $a k 7 b$ & NM_001109698 & 3.87 & 8.76 \\
\hline & eukaryotic translation elongation factor 1 alpha 1 , like 2 & eeflall2 & NM_001039985 & 2.62 & 4.51 \\
\hline & zgc:92052 & $z g c: 92052$ & ВC075870 & 2.31 & 2.10 \\
\hline & ankyrin repeat domain $6 \mathrm{~b}$ & ankrd6b & NM_194423 & 2.21 & 2.56 \\
\hline & zgc: 101737 & zgc:101737 & $\mathrm{BC} 085428$ & 2.17 & 17.75 \\
\hline \multirow[t]{7}{*}{$\mathrm{D}$} & galectin 9 & lgals 911 & NM_200072 & -9.21 & -2.85 \\
\hline & deoxyribonuclease II lysosomal & dnase2 & NM_001114738 & -4.30 & -3.98 \\
\hline & cytochrome P450 family 19 subfamily A polypeptide 1a & cyp19ala & NM_131154 & -2.52 & -11.81 \\
\hline & pannexin & panxla & NM_200916 & -2.46 & -7.22 \\
\hline & zgc: 173480 & $z g c: 173480$ & ENSDART00000106432 & -2.43 & -4.85 \\
\hline & calcyon neuron-specific vesicular protein & caly & ENSDART00000052272 & -2.39 & -2.60 \\
\hline & UBX domain protein $2 \mathrm{~A}$ & $u b x n 2 a$ & ENSDART00000128612 & -2.39 & -8.52 \\
\hline
\end{tabular}




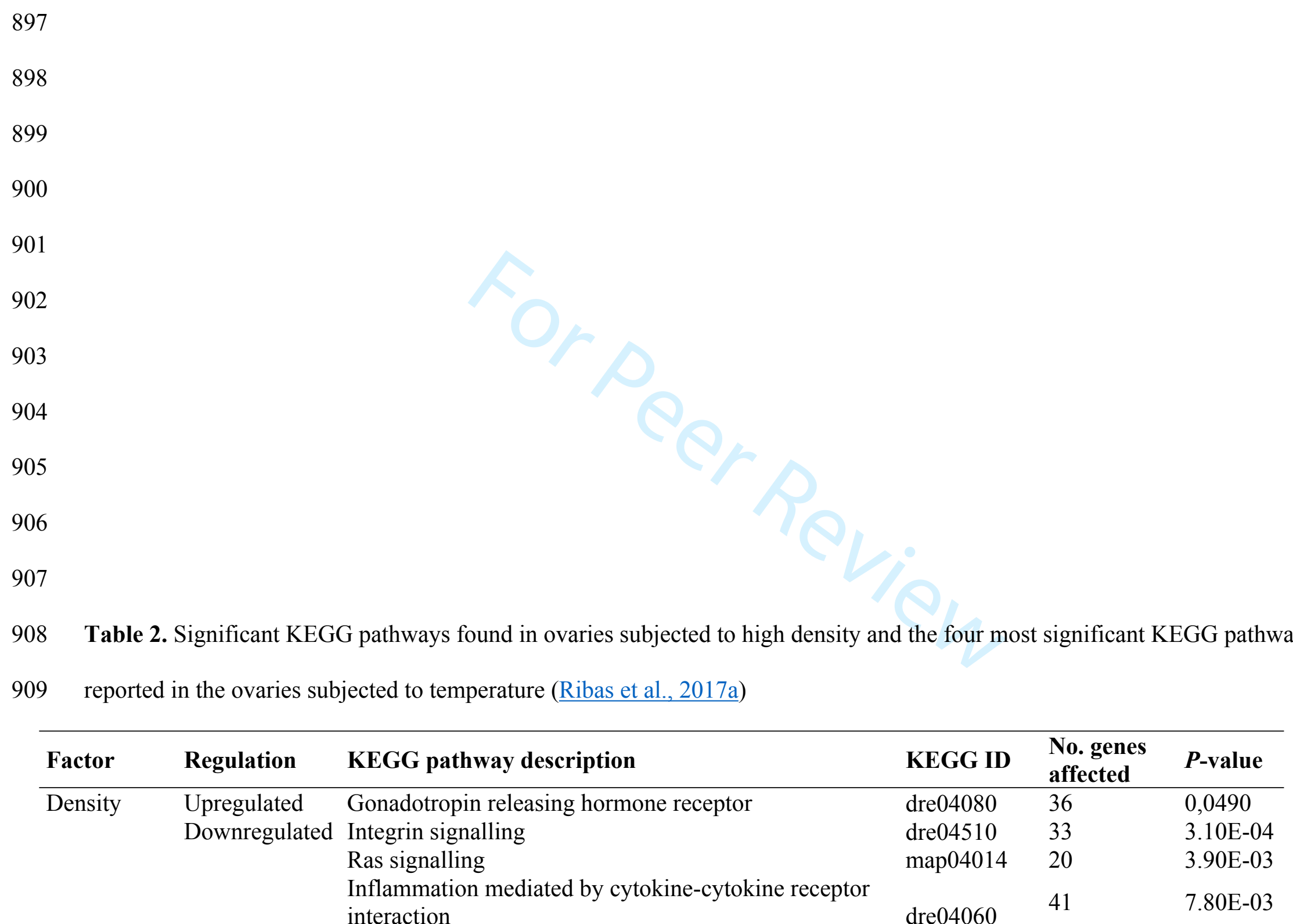


Angiogenesis

Cardiac muscle contraction

ECM-receptor interaction

Neuroactive ligand-receptor interaction

Cell adhesion molecules (CAMs)

Downregulated Protein processing in endoplasmic reticulum

ErbB signalling pathway

Ribosome biogenesis in eukaryotes

Phosphatidylinositol signalling system

$\begin{array}{lll}\text { dre } 04370 & 29 & 0,0138 \\ \text { dre } 04260 & 60 & 1.58 \mathrm{E}-04 \\ \text { dre } 04512 & 60 & 2.16 \mathrm{E}-04 \\ \text { dre } 04080 & 224 & 5.37 \mathrm{E}-04 \\ \text { dre } 04514 & 86 & 1.44 \mathrm{E}-03 \\ \text { dre } 04141 & 140 & 7.25 \mathrm{E}-10 \\ \text { dre } 04012 & 87 & 1.99 \mathrm{E}-09 \\ \text { dre } 03008 & 65 & 1.11 \mathrm{E}-08 \\ \text { dre } 04070 & 63 & 1.52 \mathrm{E}-08\end{array}$

910

911

912

913

914

915 


\section{$916 \quad$ Figure legends}

917

918 Fig. 1. Expression of sex-related genes: cyp19ala and foxl2 in ovaries (A-C) and dmrt1 and amh

919 in testes (B-D) and of the stress-related gene $n r 3 c 1$ in ovaries and testes (E-F), respectively.

920 Average values ( $n=7-8$ individuals per treatment) are shown with standard error of the mean

921 (SEM). Fold changes values are shown relative to the 9 fish/litre treatment (control). ANOVA

922 followed by post hoc Tukey test. Statistically significant differences $(P<0.05)$ among treatments

923 are indicated by letters.

924

925 Fig. 2. Gene expression represented by heatmaps of (A) sex-related and (B) stress-related genes

926 in ovaries of females exposed to high density (HD, bright red) and low density (LD, blue). Key

927 color (Row Z-score) represents the level of gene expression for each gene (red: high expression

928 and green: low expression).

929

930 Fig. 3. (A) Scatter plot of the fold change (FC) values of the common 1,269 differentially

931 expressed genes (DEGs) found between density (x-axis) and temperature (y-axis). (B) Heatmap

932 of the fold change values of the 1,269 DEGs found between density and temperature in sets A, B

$933 \mathrm{C}$ and $\mathrm{D}$. The $\mathrm{n}$ indicates the number of genes found for each set. Key color (Row Z-score)

934 represents the level of FC for each gene (red: high expression and green: low expression).

935

936 Fig. 4. GO-terms associated to the common genes affected by elevated density or temperature.

937 (A) GO-terms associated to set A (red colour), (B) GO-terms associated to set D (green colour).

938 For each GO-term graph, the log size indicates the number of genes represented and the colour 
939 saturation indicates the $\log _{10}$ Fisher's P-value along the $\mathrm{x}$-axis. GO-terms are distributed in

940 multidimensional semantic similarities in the y-axis.

941

942 Fig. 5. Fold change representation of common upregulated genes of (A) single-organism

943 developmental process, (B) single-multicellular organism process, (C) anatomical structure

944 morphogenesis; and common downregulated genes in (D) macromolecule localization, (E)

945 primary metabolic process, (F) cellular metabolic process of gene ontology terms affected by

946 elevated density and temperature. " $n$ " indicates the number of genes in each case.

947

948 Fig. 6. (A) Mean fold change of the total genes found in set A and D groups for density and

949 temperature. (B) Fold change of genes involved in Wnt signalling (dre04310), homologous

950 recombination (HR, dre03440), transforming growth factor- $\beta$ (TGF- $\beta$, dre04350), oocyte meiosis

951 (OM, dre04114), p53 signalling (dre04115) and steroid hormone biosynthesis (SHP, dre00140)

952 pathways for density and temperature factors. Note tha rhoa belongs to two pathways. 


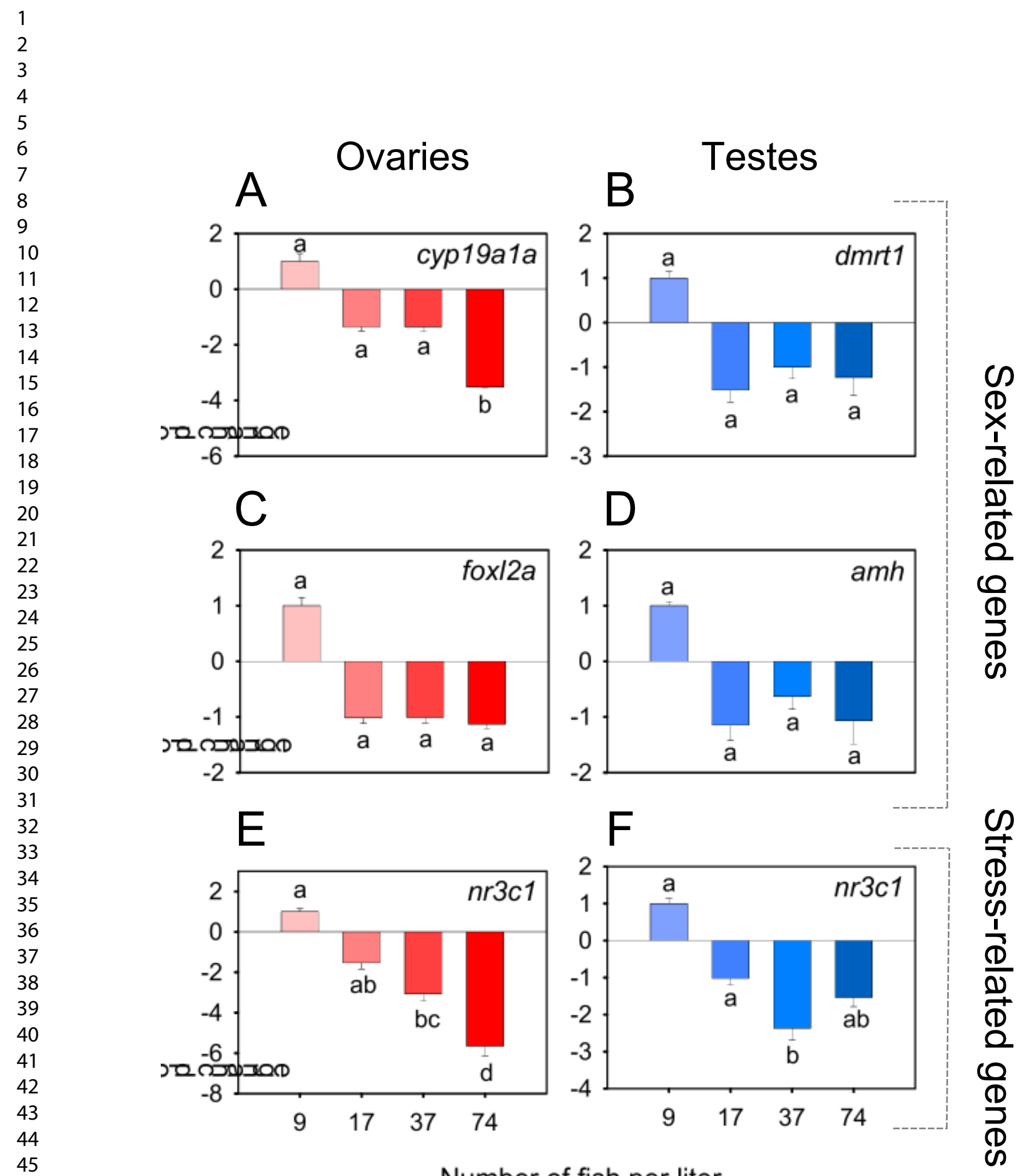

46

47

48

49

50

51

52

53

54

55

56

John Wiley \& Sons 
A

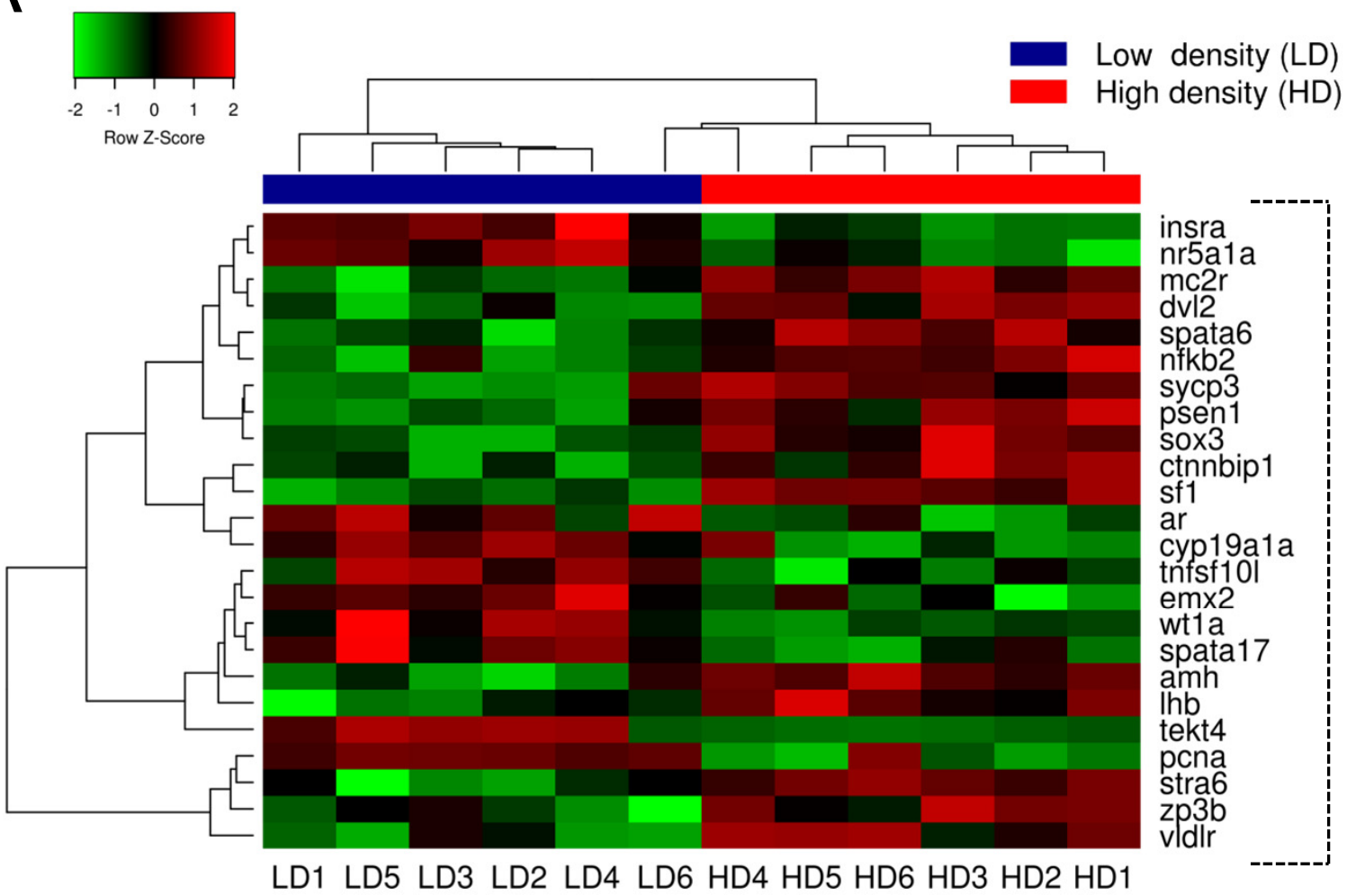

$\mathbb{D}$
$\mathbb{D}$
$\frac{1}{\mathbb{D}}$
$\frac{0}{\mathbb{D}}$
$\frac{1}{0}$
$\frac{0}{\mathbb{D}}$
$\frac{\mathbb{D}}{\infty}$

B

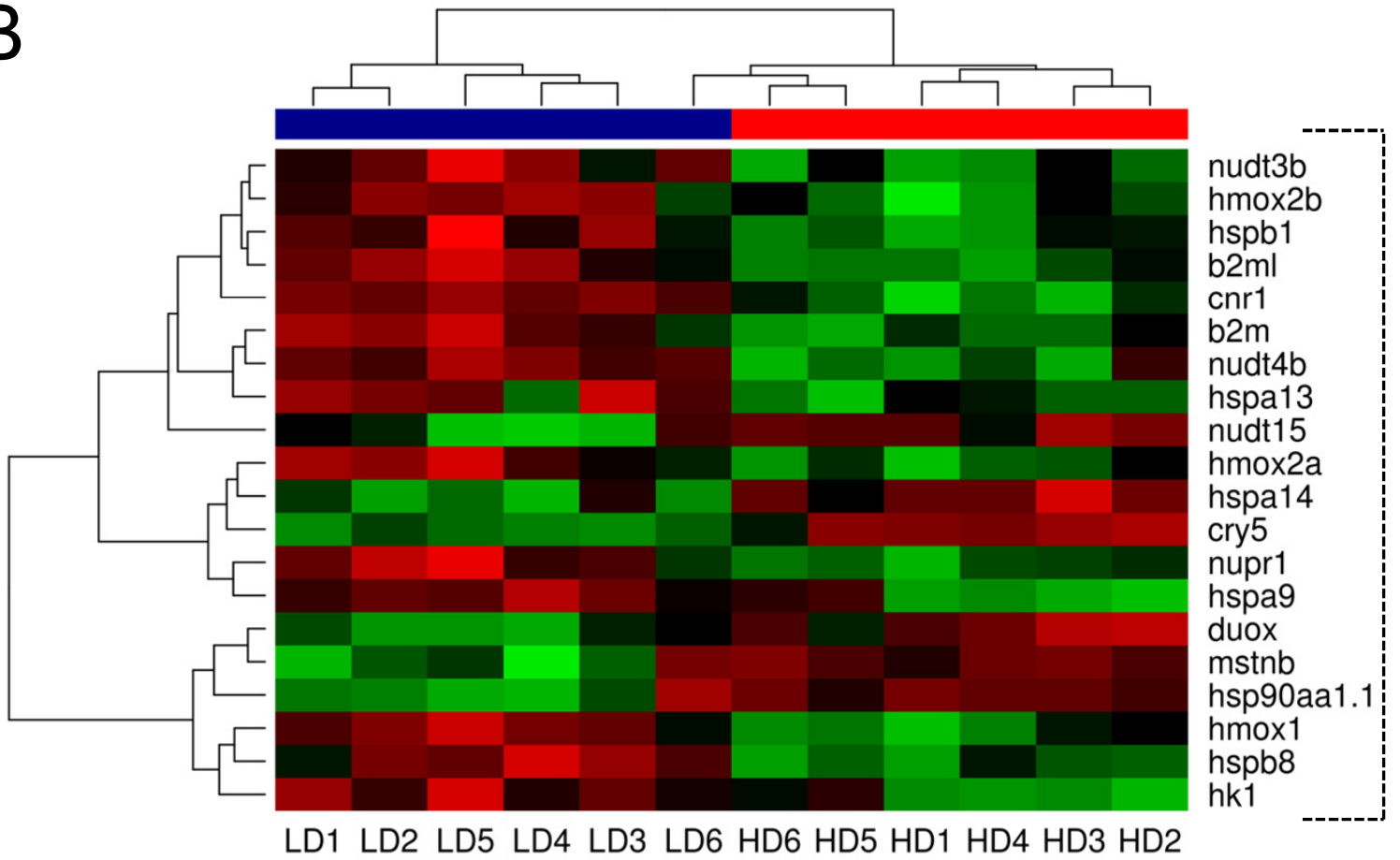

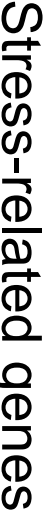




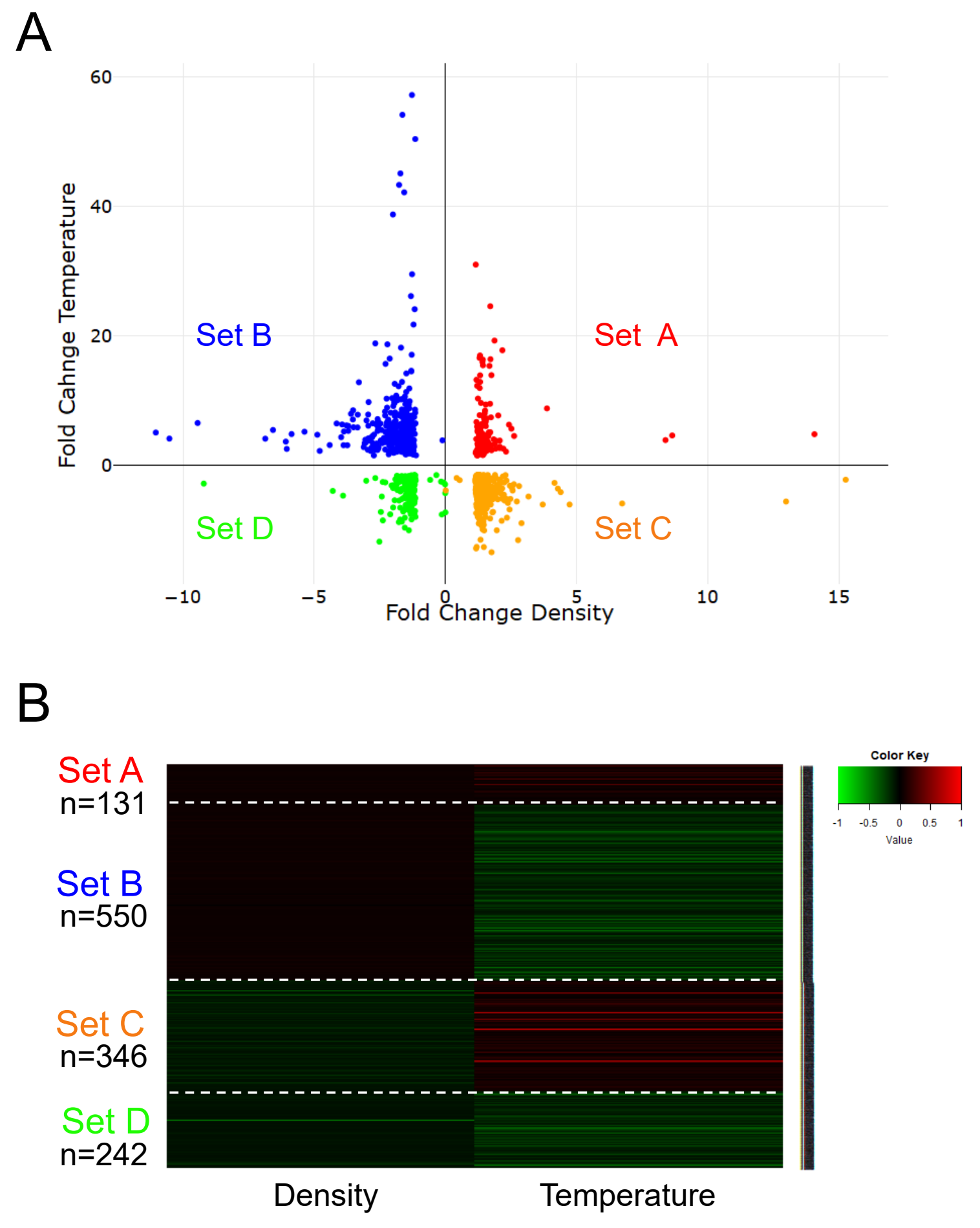



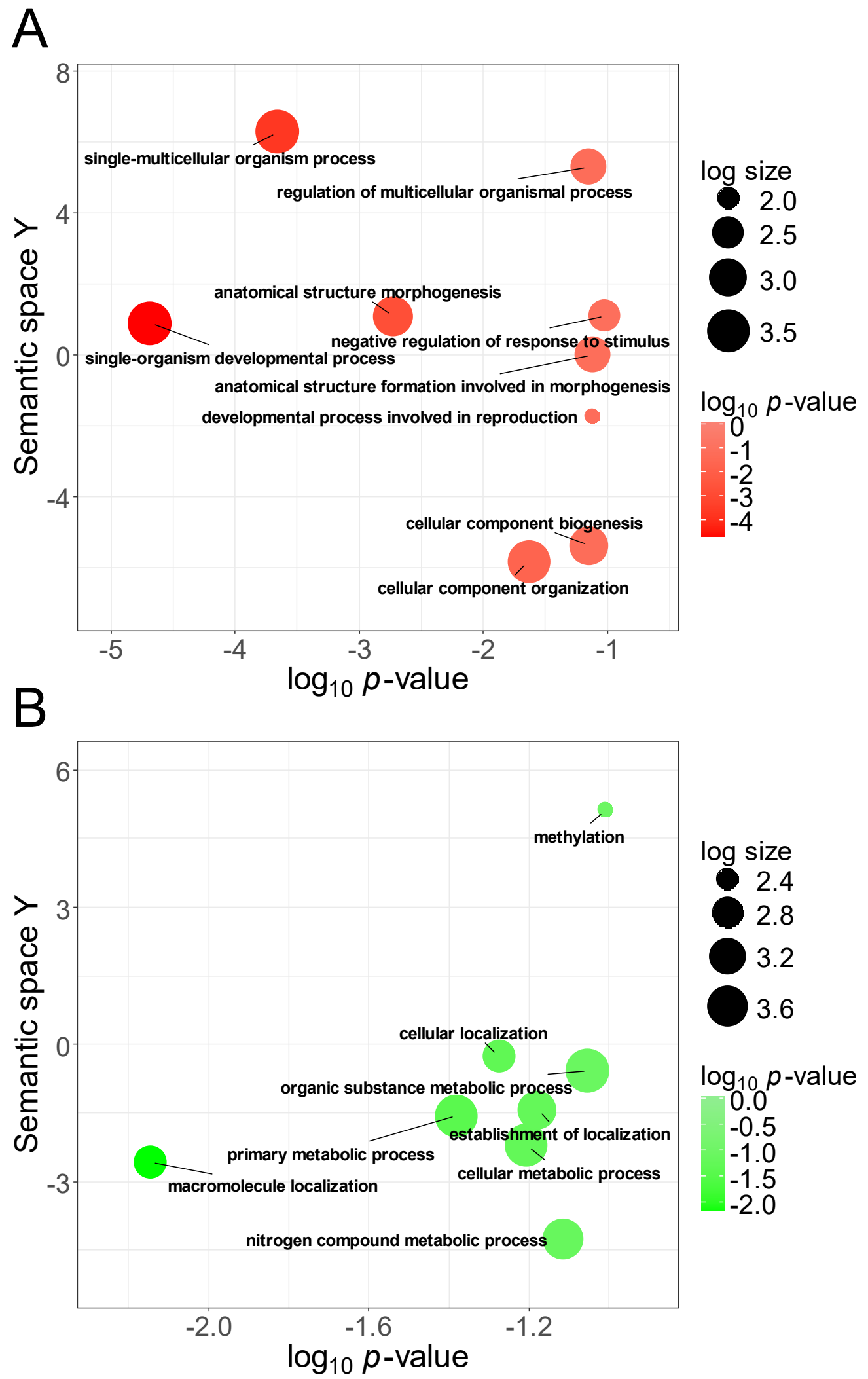


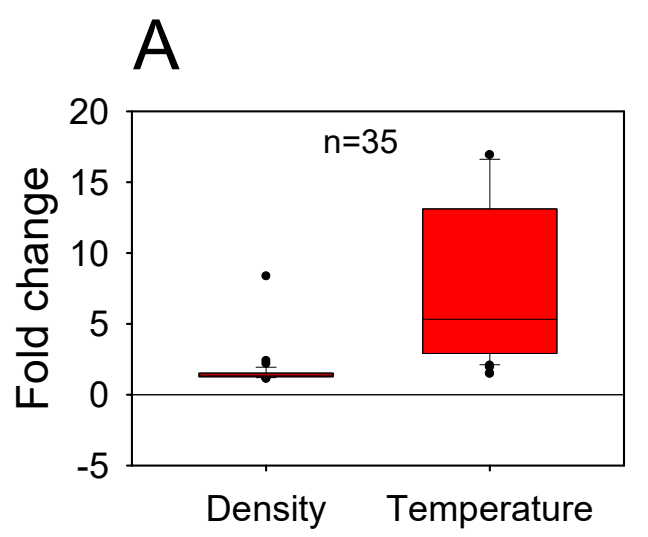

B

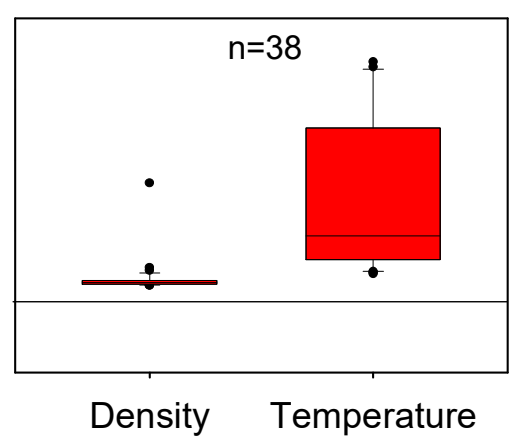

E

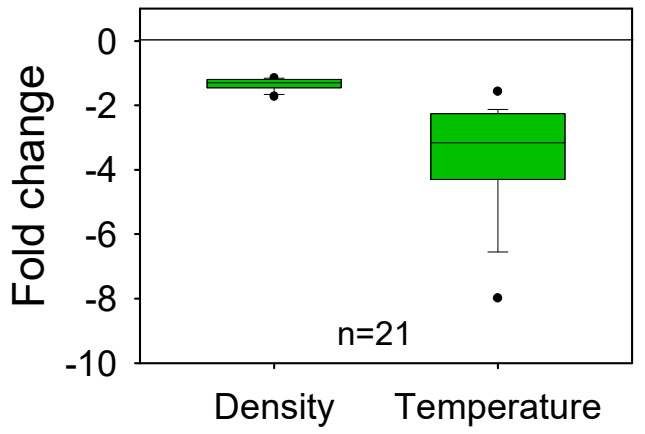

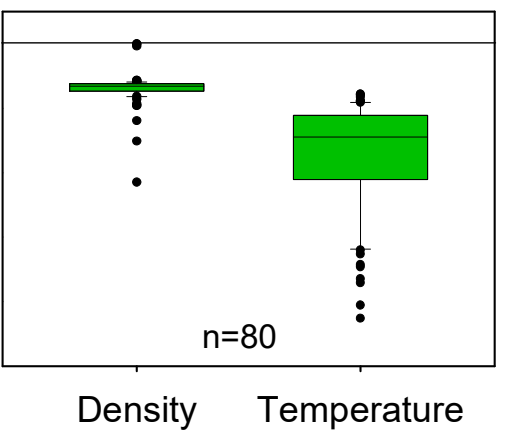

C

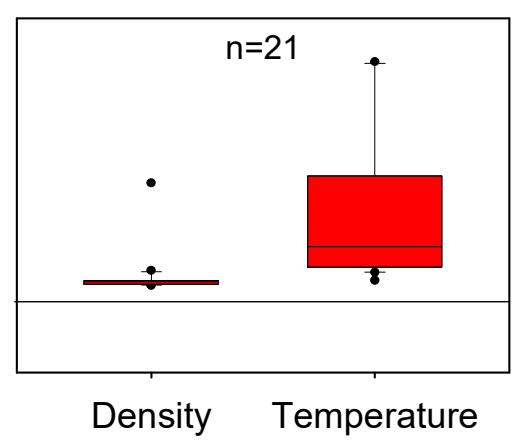

F

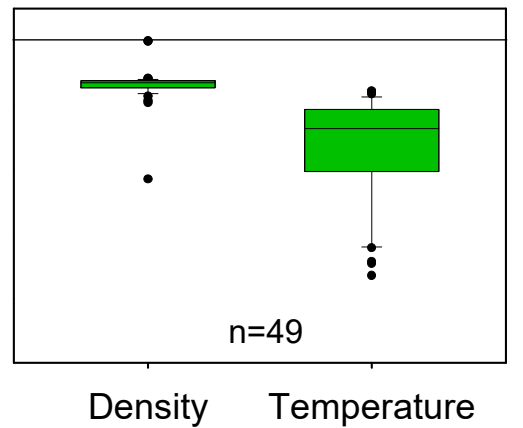


A
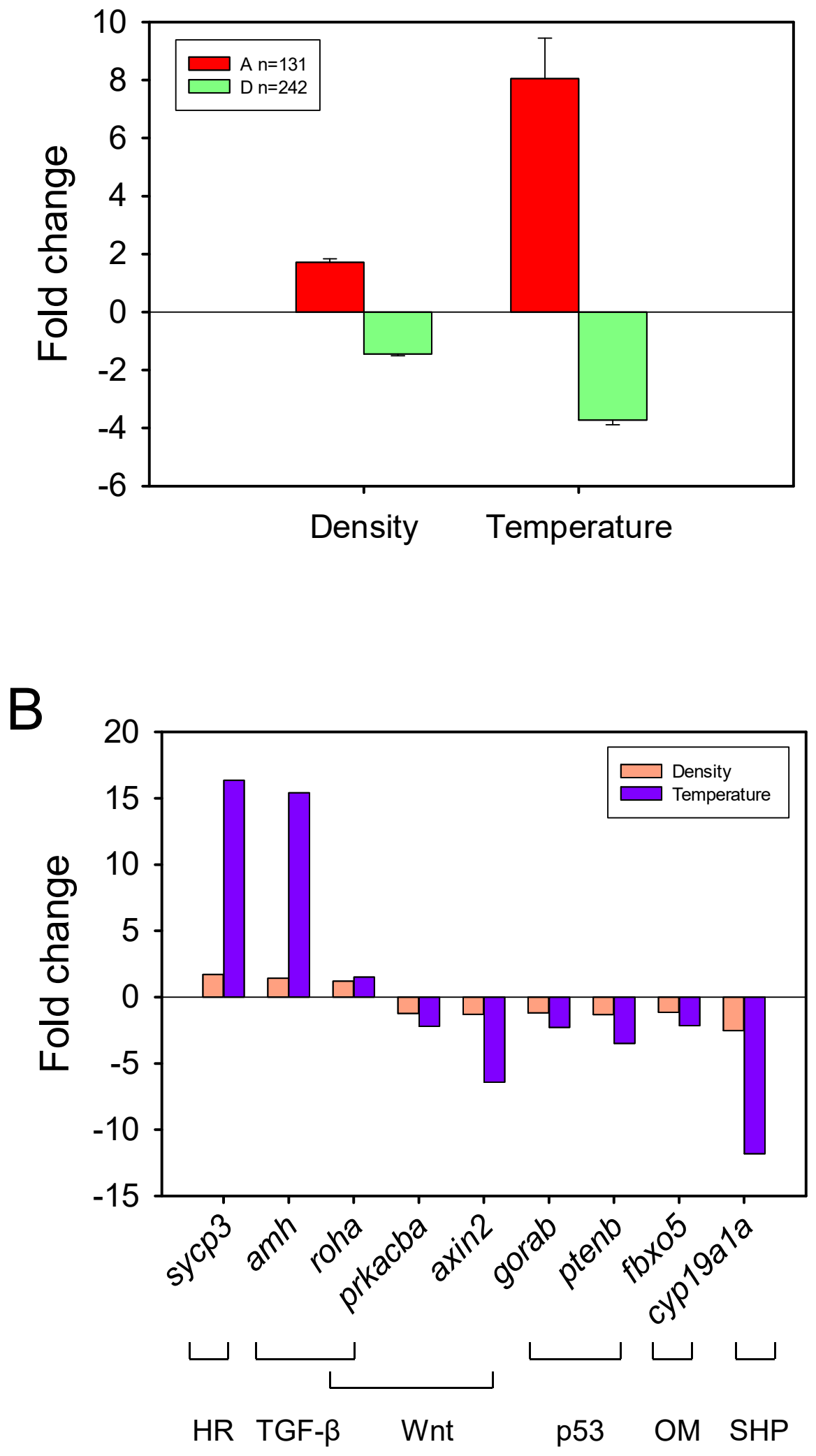